\title{
Gênero e cultura material: uma introdução bibliográfica
}

\author{
Vânia Carneiro de Carvalho
}

Museu Paulista da USP

$\bigcirc$ presente comentário bibliográfico discute as contribuições de historiadores, curadores, arquitetos, arqueólogos, antropólogos, entre outros, na produção de um tema híbrido - a história do gênero na perspectiva da cultura material. A confluência das duas áreas vem enriquecendo a compreensão da natureza cultural e materialmente sexuada das práticas sociais. Nesse casamento, no entanto, somaram-se problemas teórico-metodológicos que merecem explicitação. A carência, mesmo no quadro internacional, de obras que cobrissem diretamente o campo proposto, levou-nos a um enfoque genérico, porém extremamente fértil para o equacionamento de problemas específicos das relações de gênero e cultura material, como se pretende demonstrar. A seleção proposta reúne uma bibliografia essencialmente anglo-americana dos anos 80 e 90 e, é claro, a produção nacional. Não se pretendeu, portanto, um balanço bibliográfico de caráter sistemático, mas oferecer um quadro referencial que pudesse melhor explicitar, por um lado, a potencialidade do tema para a historiografia e, por outro, oferecer caminhos adequados para a análise da formação do espaço doméstico ocidental burguês durante o século XIX, quando espaços públicos e privados foram finamente segregados e especializados. Nesse novo contexto de aprofundamento da divisão social do trabalho e explosão da produção industrial em massa, ascensão das classes médias urbanas, a casa burguesa funcionou como um campo operacional importante na construção do gênero através de dispositivos materiais.

Cultura doméstica e gênero: uma introdução a problemas gerais

A materialidade da vida em sociedade traz para o centro do debate historiográfico fontes e problemáticas sistematicamente negligenciadas ou nem 
1. A casa americana tem sido objeto de estudo intenso na perspectiva que aqui interessa, por isso o seu destaque no presente ensaio. Além disso, o processo de aburguesamento que chega aos Estados Unidos, irradiado pela Inglaterrra e França, atinge, naquilo que são os seus fundamentos, igualmente o Brasil, isto é, altera os padrões de moradia através do aprofundamento da especialização do espaço doméstico, e com ele o maior consumo de objetos e divisões de funções relativas ao gênero. sequer suspeitadas, sem falar no enriquecimento das abordagens já existentes. Estudos sobre a produção física e simbólica dos espaços de moradia têm colocado em evidência a sua importância na constituição de categorias fundamentais tanto para a vida social quanto para dimensões pessoais como a vida psicológica e afetiva do indivíduo. São elas noções de identidade, controle, segurança e familiaridade geradas a partir de ordenações espaciais e temporais na casa e do estabelecimento de rotinas corporais (ALTMAN e WERNER, 1985; BOXSHALL, 1997; RIGGINS, 1994; ROBERTSON, 1997). Parte dessa produção, contudo, apenas circunda as questões de gênero, faltando-lhe uma aproximação mais consistente entre o uso dos artefatos e as práticas sexuadas. Mesmo assim, tais estudos apontam para o potencial de pesquisa nesta direção.

Um exemplo é a coletânea The American Home: Material Culture, Domestic Space, and Family Life, organizada por Thompson (1998) sobre a constituição do espaço doméstico americano. Nela tem-se como referencial mais abrangente a formação da sociedade de consumo americana, isto é, a criação de novas formas de expressão de status social, autoridade e poder através do consumo em larga escala de objetos. É nesta perspectiva que são apresentados resultados de levantamentos extensos, muitas vezes ultrapassando os limites do estudo de caso, para recuperar padrões de moradia e categorias de objetos utilizados em uma longa diacronia. No entanto, tais empreendimentos acadêmicos não deixam de nos dar a impressão de peças isoladas do que viria a ser uma grande colcha de retalhos à espera do arremate final. Cada investigação constitui parte de um inventário das práticas associadas à domesticidade burguesa estratégias de construção e venda de moradias para as classes médias e pobres, novos padrões de moradia para as famílias de elite, alterações no consumo de alimentos e artefatos domésticos, relações raciais, serviçais e escravistas dentro de casa, rotinas de trabalho, e assim por diante. A riqueza documental e a originalidade dos temas escolhidos contrastam, em parte, com a carência analítica destes estudos, que parecem mais preocupados com a montagem de quadros descritivos a partir de diários femininos, arquivos pessoais de famílias de elite, material publicitário, vestígios arqueológicos, plantas arquitetônicas, etc. Nesta coletânea, merecem destaque especial os ensaios Safety and Danger in a Puritan Home de Winship (1998) e A Late Nineteenth-Century Children's View of the American Home de Roth (1998), por tratarem explicitamente da formação da casa americana ${ }^{l}$ tendo como referência diferenças de gênero.

No ambiente puritano de Boston, no final do século XVII, Winship nos mostra como Samuel Sewall vivia o cotidiano familiar de um casamento de 41 anos, durante os quais ele acompanhou a morte da própria esposa e a de dez de seus catorze filhos. Analisando o diário escrito por Samuel durante todo o período de seu casamento, outro pesquisador, David D. Hall, ressaltara a representação da casa como um local de luz e paz (WINSHIP, 1998, p. 259). No entanto, Winship relê o diário de forma inversa àquela proposta por Hall, e aponta como, em inúmeros trechos do documento, são registrados, com surpresa e tristeza, os momentos de crise da família. Esses momentos são associados ao quarto, principal lugar de convívio familiar, que figura no diário somente nos casos de doença e morte, o mesmo acontecendo com a cama e o berço, seus principais móveis. A casa, segundo interpretação da autora, é para Samuel Sewall um lugar de incerteza, marcado por grandes tragédias familiares que fogem ao seu controle. A maior delas, as perdas de filhos aparentemente saudáveis, acompanhadas de incidentes 
como incêndio ou danos causados por chuva forte. A representação masculina da casa dos Sewall interessa-nos por duas razões, uma delas explicitada no estudo. Os momentos registrados no diário são todos pontuais e absorvidos com surpresa. Assim, não há menção aos processos de gestação, mas aos momentos de nascimento. $\bigcirc$ desenvolvimento das doenças não é narrado, mas somente o momento da cura ou do desenlace. Esta forma de representação indicaria um distanciamento masculino da vida doméstica. Não há nenhum registro semelhante da esposa de Sewall, ficando no ar a pergunta de como seriam os diários se produzidos por ela. A falta de documentação nos faz questionar o caráter sexualizado da preferência masculina pelo evento em detrimento da percepção (feminina?) do processo. De qualquer forma, o que está sendo colocado em dúvida é a representação da casa como um local de tranqüilidade. A análise enviesada de Winship nos alerta para o meio instável sobre o qual se constituiria no século XIX a idéia do ambiente doméstico como fortaleza e refúgio de privacidade, em oposição ao mundo externo do trabalho e do caos urbano. Será preciso exilar a morte nos hospitais e contar com os avanços da medicina preventiva, representada pela atuação militante dos médicos higienistas no gerenciamento feminino do lar, para que este tipo de representação possa vingar.

As diferenças de gênero na constituição da domesticidade e na formação do perfil de consumidores são preocupações presentes no estudo das casas de bonecas de papel (Scrapbook Houses) feito por Roth. Os álbuns foram produzidos por ou para meninas da classe média americana de seis a doze anos, durante a segunda metade do século XIX e início do XX. A partir de uma amostragem de 21 casas montadas em brochuras, cujas páginas eram preenchidas com recortes de ilustrações de móveis, objetos decorativos, elementos humanos e arquitetônicos, podendo chegar a 40 cômodos distintos, a autora nos mostra o potencial pedagógico das casas de papel. As meninas aprendiam a exercitar o gosto, fazendo o seu próprio projeto decorativo. Elas tinham que compatibilizar funções e estilos com as tipologias de objetos oferecidas pelo mercado. Treinavam para ser boas donas-de-casa e eficientes consumidoras. Há ainda uma breve menção aos cômodos masculinos, como o quarto de jogos e o quarto de menino, onde troféus e equipamentos esportivos como raquetes de tênis, luvas de baseball e floretes de esgrima aparecem como seus ícones. Investigações sobre as formas de ordenação dos objetos na casa, a confecção de trabalhos manuais, as teorias sobre decoração e suas relações com o sistema de artes fornecem elementos fundamentais para a compreensão das práticas sexuadas nos ambientes domésticos. mapeamento das transformações na organização material da casa é feito através das mudanças de estilos discutidas no campo da arte, deixando-se em segundo plano, porém sem abandonar, as suas conexões com as práticas sociais vivenciadas nestes espaços. Reflexões desta natureza são fundamentais, mesmo quando não voltadas diretamente para as diferenciações sexuadas. Elas analisam as formas materiais de produção da individualidade e a difusão maciça de tal modelo de comportamento através do incremento do consumo de artefatos domésticos no contexto de uma crescente industrialização.

Kinchin (1996), no artigo Interiors: Nineteenth-Century Essays on the Masculine and Feminine Room, sobre a formação dos ambientes domésticos ingleses, trata em termos materiais da formação da intimidade da família nuclear burguesa, processo que explica, por exemplo, as funções de nidificação do lar que couberam à mulher e as estratégias de exibição do status da família por ela 
2.O boom dos hobbies na sociedade norte-americana aconteceu muito mais tarde, na década de 1950 , impulsionado pelo ócio impingido a muitas famílias na época da Depressão (MARLING, 1994, p. 2).

3. "But when those ties weakened, the family structure itself was subject to erosion and ultimate dissolution: the divorce rate rose steadily and alarmingly after the turn of the century, and intact families, the experts concluded, were those that had learned to compensate for the loss of purpose by reorienting the institution toward meeting the emotional and affectional needs of its members" (MARLING, 1994, p. 3) praticadas. Nesta perspectiva, a autora reflete com segurança sobre as apropriações sexuadas dos estilos de decoração produzindo interiores residenciais que, para cumprir as demandas das funções sexuais, mesclaram diferentes propostas estilísticas como o uso dos estilos franceses considerados femininos para a sala, e o sóbrio estilo inglês para as salas de jantar.

Vários ensaios da coletânea The Arts and the American Home, editada por Marling (1994), sobre o espaço doméstico americano tratado no contexto da produção e consumo artísticos, deixam pistas para uma revisão, sob a óptica do gênero, das várias mudanças ocorridas no interior das residências no final do século XIX até a década de 30 do século XX. Uma delas é a intensa utilização de pinturas nas residências entre os anos de 1870 e 1880, e, posteriormente, - seu gradativo abandono, interpretado como uma tendência à despersonalização e à perda de interesse por objetos pontuais, substituídos por peças mais "decorativas" e simplificadas, valorizando-se o arranjo do espaço em detrimento da "obra de arte". Destacam-se também outros fenômenos, como a aceitação de reproduções e as regras de alocação dos temas e técnicas pictóricas nos diferentes cômodos da casa (BROOKS, 1994); o uso de fotografias como artefatos decorativos em sintonia com o mobiliário da sala de visitas, suas funções na popularização de valores afinados com as aspirações burguesas à cultura e ao cosmopolitismo (WAJDA, 1994); a incorporação dos movimentos estéticos nos trabalhos manuais femininos (GORDON, 1994); o estudo das mudanças dos sistemas de cores adotados nos interiores de salas de visitas e de jantar e sua relevância para a constituição da noção de harmonia no arranjo dos objetos decorativos; as discussões sobre estilos de decoração analisados à luz de manuais de orientação na tentativa de compreender as críticas à estética vitoriana e ao ecletismo ou as reivindicações dos chamados "reformadores" no campo da arte decorativa, que vão desaguar em movimentos como Arts and Crafts e Modernismo (AYRES, 1994).

ensaio de uma das organizadoras, Marling, que abre a coletânea, From the Quilt to the Neocolonial Photograph: the Arts of the Home in an Age of Transition, mostra-nos que a fertilidade de tais estudos para o recorte que nos ocupa pode ser vislumbrada com uma simples pergunta. Por que a casa sobreviveu à perda gradativa de funções econômicas, políticas e culturais, responsáveis pela manutenção dos laços familiares? Paradoxalmente, durante o período em que se inicia o esvaziamento de suas atividades mais pragmáticas, há um incremento assustador no aparato doméstico. No contexto norte-americano, a transformação das funções familiares tornara-se objeto de estudo de sociólogos já nos anos 20 e era preocupação governamental nos anos 30. Ao esvaziamento das funções produtivas domésticas que tradicionalmente caracterizaram a unidade familiar rural do início do século XIX, segue-se a segregação das atividades culturais gradativamente deslocadas para a arena pública, até chegarmos à indústria do entretenimento. A prática de tocar música, declamar textos, ler em família, confeccionar trabalhos manuais é substituída pelo consumo de produtos acabados². Marling aponta a noção de interioridade psíquica do indivíduo como a chave para se compreender as novas estratégias de reprodução do sistema, que cabem à família ${ }^{3}$. Nos dias de hoje, tais deslocamentos de objetivos nos parecem absolutamente normais, já que o espaço da casa como lugar de preservação, desenvolvimento e estabilização psíquica tornou-se uma vivência inculcada há várias gerações. 
Os trabalhos voltados para a presença da arte e decoração na casa trazem elementos fundamentais para a compreensão do desenvolvimento progressivo da cultura material doméstica burguesa no sentido de sustentar as demandas individuais. A casa da segunda metade do século XIX organiza-se de modo a dar pleno impulso à expansão da subjetividade, que constitui a identidade de cada membro da família, e a mulher é peça central neste processo, como consumidora, agente e intermediária. Ao lado das atividades domésticas de processamento de matérias-primas, e das atividades educacionais e culturais, a dona-de-casa vai se empenhar em constituir um espaço capaz de sustentar as manifestações pessoais de seus familiares. A instrumentalização da casa para este fim só fortalece o papel da decoração doméstica, ao contrário do que, por vezes, possa parecer. Quando autores como William Ayres observam a perda de importância da pintura como obra-de-arte no espaço doméstico le conseqüentemente a perda de sua função educativa), substituída por peças de simples "efeito" decorativo, não se percebe que a produção do efeito é fundamental para criar um ambiente propício para induzir a passagem do mundo externo do trabalho e da vida pública e urbana para aquele da privacidade e interioridade. $\bigcirc$ espaço decorado funciona como um gatilho, acionando os mecanismos de reconhecimento, harmonia, proteção e resguardo necessários para que as demandas internas dos indivíduos possam encontrar formas de expressão e interação com os demais membros. Os estudos sobre decoração residencial, estilos, produção artística, estruturas arquitetônicas, modos de vida são instrumentalizantes e conformam as questões de gênero ligadas à cultura material doméstica. Repensálos dentro dessa perspectiva permite trazer ao quadro de mudanças vividas entre homens e mulheres novos fatores explicativos.

Ardener (1 997), organizadora da coletânea Women and Space, nos introduz no universo heterogêneo dos estudos transculturais, mostrando-nos o paralelismo existente em diversas culturas na relação entre formações sociais e noções sexuadas de espacialidade. A presença da categoria gênero em diferentes culturas expressa a força estruturante que a sociedade reconhece e constitui a partir das diferenças sexuais. Mais do que buscar similaridades, para o historiador da sociedade ocidental burguesa, as abordagens comparativas permitem que problemáticas pouco visíveis em nosso contexto cultural emerjam a partir de sua relevância em outras culturas.

É o caso da investigação das relações entre tempo, espaço e gênero. Para os Matapuquio (Peru), apresentados por Skar (1997) no artigo Andean Women and the Concept of Space/Time, as representações de gênero estão ancoradas no conceito de pacha, que funde a noção de tempo e espaço constituída em uma região delimitada por água e montanhas íngremes. Os habitantes de Matapuquio, que vivem da agricultura, aprenderam a cultivar, associando os diferentes ecosistemas presentes em cada altitude com a maior ou menor velocidade de maturação daquilo que foi semeado em toda a encosta das montanhas, dividida em três zonas de cultivo. $\bigcirc$ trabalho temporário e assalariado (sistema de hacienda) na parte mais baixa do vale é exercido somente por homens. A parte mais alta das montanhas são áreas femininas de criação de porcos, ovelhas e cavalos, através dos quais as mulheres, assim como os homens, podem obter dinheiro com a venda de queijos ou dos próprios animais. As duas pontas da encosta oferecem perigo: na hacienda, ao pé da montanha, o contato com brancos e mestiços e a inserção em um sistema produtivo alienígena 
ameaçam o sistema tradicional de subsistência da vila; no alto da montanha, por sua vez, os bandidos procuram esconderijo e saqueiam as vilas. As duas extremidades também estão associadas a forças espirituais. A vila, situada no meio da encosta, onde se cultiva o milho, é atravessada por um rio que divide a cidade em duas metades. Por causa do sistema de irrigação, as 200 casas são dispersas, havendo somente um único ponto de união, no centro, onde são feitas as comemorações. Casamentos, festas, sistemas de segurança e projetos comunitários são tratados sempre entre as duas partes. Assim, a unidade perceptiva entre tempo/espaço/gênero é decorrente de uma visão de mundo dualista, produzida por atividades econômicas associadas à movimentação rotineira das mulheres para o alto das encostas e dos homens para o baixo delas e reificadas na organização social da vila.

Tempo e espaço são categorias também analisadas no estudo sobre as freiras carmelitas de Drid Williams. Citado por Ardener (1997, p. 7) em Ground Rules and Social Maps for Women: Human Behavior and Environment, Williams mostra-nos como esta interação pode atingir o que se denominou "mapa interior". Segundo controle da autora, durante mais de meio século de vida as freiras estiveram, sempre nas mesmas horas, milhares de vezes nos lugares que faziam parte da sua rotina, o que significa que tempo e espaço são por elas vividos como dimensões homólogas. Mais do que isso, diferentes locais e tempos correspondem a diferentes "espaços" de natureza espiritual e psicológica.

Gilchrist (1997), em seu livro Gender and Material Culture. The Archaeology of Religious Women, que se destaca pelo uso exaustivo dos vestígios arqueológicos aplicados às questões de gênero, indica a mesma direção nas suas análises sobre a vida da mulher inglesa nos mosteiros medievais, ou seja, a de que a renúncia à personalidade, sexualidade e status social pressuposta nos votos religiosos implica uma coletivização da experiência antes individualizada, e a materialização da vida espiritual certamente colabora para a conformidade à nova vida comunitária.

No mundo laico, Scanlon (1995), também em estudo de fôlego publicado sob o título The Ladies' Home Journal, Gender, and the Promises of Consumer Culture, disseca fenômeno semelhante em sua análise sobre o periódico norte-americano e que diz respeito à forma paradoxal de produção da sociedade de massa. Ao mesmo tempo que a imprensa colocava diante das leitoras femininas um mundo onde a sua escolha individual ganhava reconhecimento e era estimulada pelo consumo, ela desenhava a "mulher americana" (average women) a partir de critérios excludentes de raça, idade, situação matrimonial, nacionalidade e classe social. A esse perfil restritor aliava-se uma visão de mundo programática, cujo teor pode ser interpretado muito mais como um convite à adequação do que uma real iberdade de escolha. Assim como na vida das religiosas, as estratégias homogeneizadoras estão presentes no cotidiano doméstico das casas burguesas nas décadas próximas ao 1900, quando a distribuição de tarefas em espaços e com artefatos progressivamente especializados são enquadrados em rígidas rotinas que dividem o tempo de crianças, homens e mulheres. A cultura doméstica atua na formação de um território subjetivo cada vez mais sofisticado e fundamental para a sobrevivência da estrutura familiar. Ao mesmo tempo, um movimento contrário à tendência de diferenciação coloca limites através da criação de parâmetros socialmente controladores - sentidos de ordenação, ritmos e espaços previamente determinados. 
Na introdução aos estudos transculturais de gênero, Ardener afirma que mesmo em situações onde as diferenças sociais são delineadas por castas e as distâncias marcadas, portanto, por graus de parentesco e compadrio - caso típico em que o mapa social não coincide com o mapa espacial, tomando as palavras da autora - a mulher teria uma inserção social diferente do homem. Estaríamos aqui diante de uma característica comum a todas as culturas? "The foregoing examples [...] show that for any given society the life-map for women may differ markedly from that of men in the same society" ${ }^{4}$ (p. 19).

Dualismos, fetichismos, descontextualizações: problemas metodológicos

Os sistemas duais de classificação social associados ao espaço e identificados como parte da estrutura de funcionamento de sociedades simples pode dificultar a compreensão de determinados fenômenos sociais nas sociedades complexas, quando aplicados a elas sem flexibilidade ou mediações. Bipartições como esquerda e direita associadas a partes do corpo, como as mãos, agregam sentidos de gênero e seus atributos são verticalmente organizados em relações de oposição como vida/morte, belo/feio, dentro/fora, bom/mal, sagrado/profano, e assim por diante (NEEDHAM apud ARDENER, 1997). E certo que na sociedade ocidental oitocentista e mesmo no século XX podemos pensar em esteras masculinas/ femininas, espaços privados/espaços públicos, etc.

Sahlins (1979, p. 199), em Cultura e Razão Prática, livro dedicado ao que ele expressou como uma "explicação cultural da produção", propõe em um de seus capítulos a análise do vestuário segundo as regras da lingüística saussuriana, uma sintaxe definida como "um conjunto de regras de declinação e combinação das classes de forma-vestuário de maneira a formular as categorias culturais". Muitos dos chamados "contrastes significativos" são pautados sobre um Quadro de combinações binárias e em oposição a outros conjuntos binários ${ }^{5}$ de tecidos, cores e texturas. A feminilidade da seda se constitui em oposição à masculinidade da lã ou do brim, ou o excesso de ornamento aplica-se para a mulher em oposição à simplicidade do homem. Uma roupa abotoada do lado direito torna-se apropriada para os homens e interditada para as mulheres. Porém, Sahlins, ao contrário dos sistemas binários cristalizados, criticados por Gilchrist ${ }^{\dagger}$ (1997, p. 203-204), já mencionada, mostra-nos que os termos de oposição são cambiantes conforme as diferenças que se quer expressar. A mesma lã que distingue o homem da mulher, pode distinguir uma jovem mulher de sua igual mais idosa. Categorias de homossexualidade podem ser expressas na indumentária a partir de combinações de peças femininas e masculinas, resultando em seis ou mais sexos visíveis formalmente observáveis.

Um exemplo da camisa-de-força que a estrutura binária impõe à análise documental pode ser observado em The Archaeology of Gender, um estudo da sociedade novaiorquina entre os períodos de 1780 e 1840, empreendido por Wall (1994). Preocupada em saber se a mulher teve participação ativa na constituição das chamadas "esferas" femininas e masculinas da sociedade moderna, Wall articula uma rica documentação material às tradicionais fontes textuais. Dedica especial atenção aos vestígios arqueológicos de louças, através dos quais consegue controlar um conjunto de variáveis da vida doméstica e a
4."Some people reject the idea that men and women, individually or collectively, live in different worlds. But I would suggest that it is not adequate to say that men and women merely have a different viewpoint, as if they are seeing 'the same thing' or observing the same hard 'reality'. Their social constructions and their experience of the world must often (but not always) differ fundamentally if only as a result of their accumulated experiences and the way these will inevitably affect their perceptions" (ARDENER, 1997, p. 19).

5. Conforme preconizado pelo modelo da lingüística para as composições sonoras que se tornam significativas e audíveis.

6. Roberta Gilchrist aponta a dificuldade em tratar situações de gênero no interior de esquemas binários cristalizados, quando se pressupõe que tais relações sempre se realizam por oposição entre os termos masculino e feminino, excluindo não apenas a possibilidade de existência de "fluidez e indiferenciação sexual" na divisão de tarefas, mas a construção de outras categorias de gênero como o transsexual ou o "terceiro" gênero, como é o caso dos eunucos. 
eles relaciona relatórios administrativos, censos, livros de aconselhamento, bem como documentos arquitetônicos e registros iconográficos. Sua hipótese de trabalho consiste em verificar a existência (ou não) de uma relação de causa/ efeito entre a separação do local de trabalho daquele de moradia e o incremento das atividades domésticas. Para Wall, se o incremento fosse anterior ao isolamento espacial e funcional da casa em bairros puramente residenciais, as mulheres teriam desempenhado um papel ativo na divisão social de gênero que se implantava, já que a dedicação e conseqüente expansão e enriquecimento dos rituais de domesticidade não seriam simples imposição de uma situação consumada de isolamento. Para encaminhar sua hipótese Wall apóia-se nas seguintes constatações: o declínio no número de nascimentos, interpretado como valorização da prole; aumento no número de mulheres como serviçais na casa, considerado expressão de investimento direto na constituição de um ambiente de conforto e requinte; substituição do Federal style, aplicado a todo tipo de casa, por estilos neoclássicos diferenciados que permitiam a explicitação das novas divisões funcionais e sociais, culminando na formação de bairros socialmente e espacialmente homogêneos; e, por fim, aumento de investimento monetário e decorativo na louça do jantar, equiparando-se ao investimento nos serviços de chá. Excetuando-se as alterações arquitetônicas, todas essas mudanças ocorreram anteriormente à separação da moradia do local de trabalho, o que indicaria a participação ativa da mulher da classe média na constituição da "esfera" feminina da cidade. Para as famílias abastadas, a segregação espacial teria acontecido anteriormente e mais cedo do que para aquelas famílias da classe média. Para Wall, as variações estilísticas e a tipologia de artefatos alocada em cada cômodo da casa expressam sentidos e práticas diferenciadas das mulheres. Na sala de jantar ela é a representação do esteio moral da família; na sala de visitas e no hall, ela é a negociadora da inserção da família na sociedade e o seu cartão de visitas. As diferenças decorativas entre a louça de jantar e a de chá explicam-se também desta forma. Até mesmo os bairros residenciais e sua arquitetura específica seriam, no seu conjunto, expressão da esfera feminina do privado. A arena pública é masculina e estaria não apenas fora de casa, mas nos bairros comerciais e industriais.

Aqui, o confronto bibliográfico permite algumas considerações no intuito de evitar reduções que a binariedade pode causar nas reflexões sobre gênero. A demonstração de existência de atitude feminina ativa na escolha da louça, na contratação de empregadas e assim por diante, não significa necessariamente que a mulher estivesse negociando a implantação de um modelo próprio, feminino. Atividade não pode ser confundida com um projeto consciente de mudança de atitude, problema que fica claro na maneira como Gilchrist apresenta o conceito de habitus de Pierre Bourdieu para explicar o caráter dual das relações da categoria gênero com a cultura material. Sua natureza é estruturalmente determinada, porém realiza-se através do agenciamento individual, o que possibilita não apenas a adoção da prática consensual mas, por vezes, a divergência:

Their actions were governed by an unconscious 'learned ignorance', or habitus, which provides agents with a practical logic and sense of order. In other words, women acting on their own common sense knowledge of the world around them, their habitus, would reproduce structural relations and yet possess the freedom which sometimes would lead to opposition and social change. (GILCHRIST, 1997, p. 14). 
A abordagem de Wall parece querer "julgar" os agentes históricos demonstrando que as mulheres foram co-responsáveis com os homens na especialização das práticas e espaços urbanos.

Wall também não explica por que as mulheres da classe média residentes em casas onde ainda funcionavam de forma unificada moradia e trabalho não poderiam estar se orientando pelas mesmas mudanças já ocorridas nos estratos sociais mais abastados. Por último, e o que nos parece mais comprometedor, a formação de "esferas" feminina e masculina em uma sociedade complexa como a nossa não parece estar satisfatoriamente tratada se não considerarmos que o homem também perde espaços de sociabilidade antes vividos nas ruas e locais públicos de encontro da cidade. Ele também será reorientado para constituir seu espaço de afetividade e vivência privada dentro de casa. Wall (1994, p. 1 14) provavelmente tem razão quando diz que a mulher de classe média domina o ritual do jantar, se considerarmos que para alguns desses segmentos o grau de confraternização não extrapolava o círculo restrito dos parentes e amigos mais próximos, como no caso das famílias onde ela constatou não haver investimento em uma louça de chá diferenciada e mais requintada. Neste caso, os aspectos comunitários da refeição seriam priorizados em detrimento daqueles associativos ${ }^{7}$. Ao diferenciar os dinner parties dos family dinners, nos quais os primeiros seriam conduzidos por homens e os segundos por mulheres, Wall abandona a primeira modalidade e se dedica a desenhar de forma radical a constituição daquilo que seriam as "esferas" masculina e feminina, pensadas como enclaves sociais e de gênero.

Kinchin (1996), já citada anteriormente, analisa a decoração dos ambientes domésticos ingleses do século XIX para demonstrar como as diferenças nos atributos materiais nas áreas públicas da casa - uso de matérias-primas, intensidade da ornamentação, escolha entre o estilo francês ou inglês, grau de instrumentalização dos artefatos, contrastes formais e associações explicitadas em manuais de etiqueta - indicam que a sala de jantar oitocentista apresentava-se como um espaço masculino e a sala de visitas feminino.

Por outro lado, em A More Humane History of Home, Lawrence (1 985) reconhece os limites da análise da arquitetura doméstica na compreensão das formas de uso de seus cômodos e busca na literatura australiana do século XIX descrições que nos mostram como regras e normas de ocupação da sala de visitas, por exemplo, são aplicadas cotidianamente, restringindo o acesso de crianças a este espaço quase sempre vazio e sem vida, onde a sala de jantar assume a função de "verdadeira" sala de estar.

Na perspectiva transcultural de Ardener, a associação da mulher ao espaço doméstico apóia-se, em parte, nas noções de espaço perigoso e espaço de segurança, que são comumente associados a gêneros e faixas etárias. A linha que demarca o início do primeiro e o término do segundo pode variar. Há comunidades como a dos Andes peruanos que percebem como segura toda a vila e o seu entorno, nas encostas dos morros. $O$ alto das montanhas e seus vales, zonas de perigo, são evitadas, especialmente pelas mulheres. Em outro contexto, a percepção do ambiente externo como não confiável permite entender a reclusão no ambiente doméstico de mulheres, e o uso do véu nas sociedades muçulmanas. As classificações binárias, quando pertinentes, deveriam manter o grau de flexibilidade próprio do sistema cultural em questão, e este grau varia muito quando saímos do contexto de sociedades estáveis para aquele das sociedades ocidentais
7. Wall refere-se às duas formas de integração social definidas porTönnies e retrabalhadas por Thomas Bender como duas formas coexistentes - $G e$ meinschaft, onde os laços são afetivos, de amizade $\mathrm{e}$ parentesco, privados e íntimos, e Gesellschaft, que diz respeito aos laços constituídos artificial mente, na vida pública, marcados pelo individualismo e impessoalidade das relações de mercado. A reprodução dos laços comunitários no ritual do jantar estariam presentes, nas versões mais antigas, na ordenação dos pratos menos estruturada, na ausência de um foco visual, na ausência de intermediários (como a presença de serviçais no servir à francesa), na visão da comida como mais importante do que a decoração dos pratos, por isso a ausência de louças de cobertura (1994, p. 4 , 117). 
capitalistas, ditas complexas. Ao contrário da rigidez de Wall na associação da esfera pública ao homem e da esfera privada à mulher, podemos pensar na afirmação de Ardener que nos lembra como um espaço privado pode se tornar público com a simples entrada de um estranho.

No trabalho de Clark (1998), Own Your Own Home. S. E. Gross, the Great Domestic Promoter, percebemos a interação existente entre interesses públicos e privados. A autora enfoca a trajetória de Samuel Eberly Gross, figura que ganhou notoriedade comercial e política como construtor de casas de médio e baixo padrão em Chicago, no final do século XIX e início do XX. Em uma de suas peças publicitárias, Gross contrasta duas imagens. A primeira, que leva o título "The Owner of a Home", ilustra um confortável ambiente de sala de estar, onde o chefe de família lê, de pernas cruzadas, o seu jornal. Ao seu lado encontram-se duas mulheres; uma delas se entretém com o bordado e a outra brinca com um bebê ao colo. $O$ ambiente, devidamente iluminado pela luz aconchegante de um abajur, encontra-se decorado com quadros, papel de parede e cortinas. A outra imagem, "The Renter", mostra uma carroça carregada com os pertences da família, que, com as rodas de trás arreadas, protagoniza um pequeno desastre: parte dos bens vão ao chão, para desespero da criança que ocupa o banco da frente. Didaticamente, a publicidade da casa própria vende a idéia do lar como reduto de tranqüilidade e segurança, contribuindo diretamente para a constituição desta esfera privada, íntima, associada à mulher. Tal divisão não deixa de ser sutilmente lembrada na imagem, já que o homem, ao ser o único leitor de jornal na cena, demonstra a sua inserção no mundo externo.

Em Appearance and Effect is Everything, Heck (1998) nos oferece outro exemplo, que demonstra a importância da casa e do ambiente doméstico para a "esfera" masculina. São descritas as circunstâncias da construção, entre 1806 e 1809, de três casas segundo o que ficou conhecido como arquitetura Virginia's Palladian, em Nelson County, ao sul de Charlottesville, no Estado da Virgínia, por três primos - Samuel, Joseph e George Cabell-membros de famílias tradicionais. Estas três casas, que se diferenciavam das demais pelo estilo, riqueza e monumentalidade, fundaram um padrão de ostentação na região que perdurou por mais de 50 anos. Através da leitura da correspondência entre parentes e amigos dos Cabell, a autora relata o empenho dos três políticos na construção de suas moradias. Além dos dividendos políticos, que explicitamente se esperava conseguir com uma tal exibição pessoal de poder e riqueza, a implantação de uma moradia diferenciada fazia parte das novas estratégias de reconhecimento social que emergiram após a Revolução. Este período conheceu um acelerado desmoronamento dos antigas hierarquias sociais. Privilégios, símbolos e rituais de poder perderam seu significado ou mudaram de mãos. $\bigcirc$ declínio do status dos fazendeiros acompanhou as sucessivas divisões de terras entre seus herdeiros, terminando por enfraquecer as antigas grandes fortunas geradas pela agricultura. As famílias da elite perderam o acesso automático aos cargos políticos. $\bigcirc$ desrespeito aos antigos representantes de poder e o anseio dos estratos médios e baixos por encontrar formas sociais de distinção deixaram os membros da elite perplexos e confusos perante as mudanças nas formas de expressão de poder. Pessoas como os primos Cabell, que perceberam a direção dessas mudanças, encaminharam-se para carreiras profissionalizantes como a medicina e a advocacia, esta última intrinsecamente ligada à carreira política. Simultaneamente, os homens da família Cabell empenharam-se em constituir um patrimônio que servisse à 
ostentação. Isaac Cole, amigo e confidente de Joseph Cabell, aponta o que estava faltando para que este se estabelecesse politicamente vitorioso em sua região - uma casa ${ }^{8}$. A construção das casas Palladian mobiliadas com os mais ricos objetos, aos quais poucos teriam acesso, foi a maneira encontrada para criar novos símbolos e práticas de distinção social que poderiam garantir-thes o lugar ameaçado pelas mudanças pós-Revolução. Em um mundo agora desconhecido ele tinha a clareza de que a exibição material era a forma de constituir autoridade e posição social. Vê-se aqui o empenho masculino em garantir seu lugar na arena pública através de um artefato ligado ao que se poderia considerar território privado e, por isso, feminino. Para além das funções de exibição, Heck nos mostra em trechos de correspondência entre homens da família a autêntica e premente necessidade de gozar periodicamente de momentos de tranqüilidade na privacidade de suas novas residências, longe da agitação e das pouco confiáveis amizades políticas?.

Os ensaios de Arpad (1988), "Pretty Much to Suit Ourselves": Midwestern Women Naming Experience Through Domestic Arts, e de Gordon (1988), Victorian Fancywork in the American Home: Fantasy and Accomodation, são exemplos de estudos que se preocuparam com a reconstituição das práticas femininas nos espaços domésticos do século XIX. A mulher é interpretada através de suas auto-representações levantadas em diários, cartas, escritos literários e objetos, especialmente as colchas de retalhos (quilts). Para fugir de uma interpretação "masculina" da história, a ênfase na experiência feminina mostra-nos como esgarçaram-se as necessárias articulações que o suposto "universo" da mulher possui com aquele constituído pelo homem. Nestes ensaios percebemos como os estudos de caso permitem abordar com riqueza de detalhes a constituição das funções femininas ao mesmo tempo que, pela própria natureza do estudo de caso, a consideração de variáveis mais abrangentes fica prejudicada. É confortável acreditarmos na existência de uma estética puramente feminina quando acompanhamos os relatos de mulheres sobre a importância da confecção das "colchas de retalhos", analisadas por Arpad. No trabalho comunitário das mulheres, Arpad identifica funções de ordenação, de controle psíquico, de reconhecimento social e perpetuação da memória individual.

Beverly Gordon, por sua vez, apresenta-nos os fancyworks. Considerados objetos de decoração doméstica confeccionados por mulheres a partir de materais de pouco valor, os fancyworks miniaturizam casas, figuras humanas ou animais agora transmutados em porta-palitos, porta-fósforos, portabiscoitos, agulheiros, etc. Considerados como um meio lúdico de exercitar a fantasia, Gordon reconhece as funções transformadoras às quais estão associadas as mulheres na produção do ambiente da casa. No entanto, suas considerações dão uma ênfase desproporcional aos objetos como uma forma feminina de fuga do enclausuramente imposto à mulher. Para isso, a autora recupera experiências masculinas como a prisão, a internação por doença ou a longa estadia no mar, onde homens teriam recorrido à produção de trabalhos manuais. É possível crermos em um isolamento tão profundo - talvez existente entre as mulheres de fazendeiros que se localizavam no Oeste americano - que teria levado as mulheres a uma alteridade autônoma daquela sobre a qual estava constituída a do homem? $\bigcirc$ exercício da fantasia, do auto-controle psíquico, da ordenação do mundo, e a própria baixa-estima social de que tais práticas são alvo não seriam fundamentais para a produção e manutenção do sistema doméstico? Como podemos imaginar
8. De Isaac Coles para Joseph Cabell: "You have been a wanderer long enough. It is now fit that you should have a home and that you should be the master of it [...]. Until you do this you can have no real weight or influence in society" (COLES apud HECK, 1998, p. 11).

9. Inversamente, a representação da mulher no espaço político é o tema de Silvia Rodgers (1997) em Women's Space in a Men's House: the British House of Commons. Ao comparar o funcionamento da Casa dos Homens entre os Iatmul da Nova Guiné e a House of Commons em 1834 e na sua atual versão, reformada depois da Segunda Guerra, a pesquisadora encontra, nesta última, mecanismos desenvolvidos para manter este espaço de natureza pública e de fundamental importância política como um espaço essencialmente masculino. Usando como parâmetros as formas radicais de exclusão da mulher nos dois primeiros modelos, e através de entrevistas e análises de discursos e documentação pessoal de seus membros, Rodgers demonstra que, apesar de teoricamente a mulher inglesa ter direitos iguais de acesso às cadeiras do parlamento, o número de membros femininos é muito reduzido e seus pares masculinos se relacionam com estas mulheres eleitas como seres fora do lugar. Sua aceitação depende do sucesso feminino em demonstrar atitudes e características consideradas masculinas, que vão, nas palavras da autora, desde a apresenta- 
ção de "idéias claras" até a capacidade de ingerir quantidades elevadas de cerveja.A experiência da gravidez e gestação, escolhida como situação de inequívoca feminilidade, deixa evidente a prática de reclassificação da mulher como homem, utilizada como estratégia para manter a preponderância masculina deste espaço. que o homem público não faça parte fundamental da vida na casa e que a ele não estão direcionadas as funções domésticas?

Os estudos das relações de gênero no recorte que mais nos interessa, ou seja, aquele do espaço doméstico - alterações de equipamentos de trabalho doméstico, de fontes de energia, de disponibilidade de mão-de-obra, de alocação e arranjo de mobiliário, de infra-estrutura sanitária, etc. - podem contribuir para o entendimento da construção material de noções como tecnologia, trabalho, conforto, limpeza, funcionalidade, individualidade, prestígio e personalidade. As coletânias organizadas por Colomina (1992), Sexuality \& Space, Grazia e Furlough (1996), The Sex of Things: Gender and Consumption in Historical Perspective e Kirkham ( 1996), The Gendered Object, apresentam estudos específicos de cultura material sob a óptica das diferenças de gênero, demonstrando a relevância desta dimensão da vida para o entendimento das categorias masculino e feminino e as mudanças nas formas de produção e apropriação de artefatos, a definição de políticas de consumo, as alterações tecnológicas, a dinâmica de produção e reprodução das desigualdades sociais. No entanto, colocar o artefato no centro da cena histórica não tem sido tarefa fácil nem para aqueles que a isso assumidamente se propõem. Problemas epistemológicos relacionados à noção de cultura material e documento material, tratados por Rede (1996) no artigo História a partir das coisas: tendências recentes nos estudos de cultura material, podem ser identificados também nos estudos de gênero. $\bigcirc$ primeiro deles diz respeito à dissociação entre o documento material e o fenômeno social, transformando o primeiro em um simples reflexo do segundo. Trata-se aqui de abordagens que, "[... concebendo um núcleo matricial, localizam na sua periferia objetos que, não tendo substância própria, dependem das transferências de atributos a partir do núcleo para compor sua identidade. $\bigcirc$ centro seria, então, o verdadeiro gerador de realidades" (p. 267).

Não se pode esquecer que o lugar de produção das matrizes que envolvem a cultura material pode variar e que a localização do "núcleo matricial" no mercado de consumo é, por vezes, um fato, aliás reconhecido na análise de fenômenos contemporâneos onde a identificação de perfis de consumidor atingiu alto grau de sofisticação e onde os consumidores são conscientemente manipulados para controle de mercado. A análise de McKeller (1996), Guns: the Last "Frontier on the Road to Equality"? sobre armas de fogo desenhadas para mulheres, mostranos como a indústria projeta no artefato as representações tradicionalmente associadas ao feminino - cuidado com as crianças, proteção do lar, suavidade e maciez traduzidas pelo uso de madeira clara e formas arredondadas - e como estas representações acabam reforçadas pela publicidade.

Em Hearing Aids: Sweet Nothings, or an Ear for an Ear, estudo de Schwartz (1996) sobre o desenvolvimento sexuado dos aparelhos para surdez, fica claro que as mulheres só usam o aparelho (que, lembremos, resolve problemas de surdez comuns a ambos os sexos) quando este é reconhecido como feminino, ou seja, quando foram incorporadas ao seu design e à sua tecnologia qualidades que o tornaram reconhecidamente feminino pelas mulheres. Tais qualidades eram basicamente a miniaturização, que permitia a camuflagem, e a sensibilidade às variações tonais, que permitia uma interpretação do discurso para além do simples significado textual das palavras.

Já Oddy (1996), em Bicycles, seu instigante estudo sobre a bicicleta como artefato de gênero, observa que a introdução do veículo em 1817, a partir de um modelo com selim colocado sobre uma barra na qual se fixavam as rodas, 
impediu a sua apropriação pela mulher, já que a barra era incompatível com as saias compridas. A restrição aconteceu apesar de não haver socialmente qualquer censura às mulheres no uso de instrumentos de locomoção mecânica como triciclos e patinetes. Quando em 1890 estabeleceu-se o modelo sem barra, que poderia ter significado um uso indiscriminado pelos dois sexos, a forma de acelerar o seu consumo pelas mulheres levou o produtor a oferecê-lo como um desenho exclusivamente feminino. A diferença de trajetória da bicicleta com aquela do aparelho para surdez é sutil mas fundamental, mostrando-nos como as relações entre cultura e produção são de dupla-mão. Ambos - bicicleta e aparelho para surdez - nasceram incompatíveis com o exercício da feminilidade. Posteriormente o aparelho para surdez incorporou as qualidades necessárias para ser aceito pelas mulheres, enquanto um modelo de bicicleta foi criado como feminino, sem nenhum respaldo nas representações vigentes sobre as qualidades de gênero. Aqui, o modelo de bicicleta sem barra se transforma em um atributo que ingressa no "universo mental" das representações do feminino.

Outro desvio conceitual no tratamento das dimensões materiais da vida em sociedade, comentado por Rede (1996, p. 272), decorre da noção de fetiche que transforma os sentidos atribuídos socialmente ao artefato em características a ele imanentes. Um exemplo de abordagens que acabam outorgando ao artefato uma autonomia que ele não tem pode ser observado no estudo de Attfield (1996) sobre a boneca Barbie ${ }^{10}$ e o boneco Action Man ${ }^{11}$. Comparando as articulações dos brinquedos, a autora demonstra como se reproduz materialmente as representações que associam o homem ao movimento e a mulher à imobilidade. As cinco articulações presentes na Barbie permitem apenas mudanças de pose, enquanto o Action Man, dono de vinte articulações, ajusta-se a movimentos complexos. As constatações e comentários, muito pertinentes, sobre a estrutura dos brinquedos ficam incompletos com a ausência de qualquer tentativa de explicar as suas formas de apropriação pelas crianças, ou, pelo menos, buscar as razões do tremendo sucesso entre elas. Um sucesso que, segundo a própria autora, contradiz o crescente questionamento dos papéis sexuais tradicionais, a pressão de fabricantes de brinquedos alternativos e as críticas ao acentuado sexismo destes brinquedos.

As lacunas induzem o leitor a compreender a "força" dos artefatos como descoladas da dinâmica das relações sociais. $\bigcirc$ mesmo procedimento é observado em estudos tipológicos, ainda mais expostos às armadilhas do fetiche. Para compreender a relevância dos artefatos para a viabilização das relações sociais, os estudos especializados - descrição funcional, morfológica e formal são fundamentais, já que esta é uma das maneiras de demonstrar as especificidades dos documentos tridimensionais com relação àqueles ligados à linguagem escrita ou verbal. $\bigcirc$ risco, no entanto, está em retirar da tipologia a sua natureza histórica, isto é, a sua qualidade de construção social específica e temporal, outorgandothe o poder de expressar autonomamente os sentidos que estes objetos portam, como é o caso de Razors, Shaving and Gender Construction, um estudo de barbeadores, basicamente classificatório, realizado por Retallack (1999). O fetiche é o caminho para a naturalização dos atributos de gênero, que passam a ser percebidos como diferenciações biológicas expressas nos objetos.

Segundo a avaliação de Rede (1996, p. 268), no tratamento fetichizado da vida material, as funções instrumentais ou simbólicas atribuídas aos artefatos são apresentadas como permanentes, ou seja, a cultura material estaria
10.A boneca Barbie teve como precursora uma boneca alemã inspirada na personagem Lilli, de um cartoom também alemão dos anos 50. A Bar bie é uma fasbion doll, tipo de boneca que existe desde o século XVIII, usada para apresentar tendências da moda a mulheres. A novidade está no fato dela ser uma boneca de moda produzida para crianças. Ela sofreu muitas modificações, inclusive aumento de articulações que permitiam maiores movimentos, porém sempre com o objetivo de aprimorar as formas de ostentação de todo tipo de vestuário $\mathrm{e}$ acessório. Como boneca da moda, a Barbie acompanhou as mudanças relativas às atividades femininas, existindo como mulher de negócios, dona-de-casa, esportista, glamorosa, e voltada para atividades de lazer. Seu corpoé o de uma teenager com formas exageradas: busto desproporcionalmente maior que o peito, pernas irrealisticamente longas, pés do tamanho das mãos, anatomicamente incapazes de sustentar o corpo (ATTFIELD, 1996,p.80-89).

11. O Action Man foi lançado nos Estados Unidos em 1964 como G. I. Joe. Em 1966 é renomeado como Action Man e lançado também na Inglaterra.Houve dúvidas quanto à sua viabilidade, já que era um boneco, brinquedo tradicionalmente feminino. No entanto, alcançou grande sucesso, apesar da aparência irrealista, comprometida pela necessidade de possibilitar um grande número de movimentos (ATTFIELD, 1996, p. 80-89). 
associada àqueles valores mais fundamentais da experiência humana, e por isso universais. No nosso caso, tais problemas insinuam-se na análise de Schoeser (1996) sobre roupas femininas - Legging it. Em uma retrospectiva de 600 anos, passando por gregos e romanos, pelo Renascimento e a França do século XVIII, a autora percebe uma permanência de sentidos altamente positivos - como poder, autoridade, razão, juventude, ambição, destreza física e elegância - associados às roupas que delineavam as pernas masculinas. Com base nesta tradição nobre de expor as pernas, a autora procura identificar na adoção das meias-calças e mini-saias por mulheres uma atitude muito mais radical e cheia de sentidos de autonomia e liberdade, do que o uso e os sentidos associados às calças compridas femininas. Num esforço que chega à militância, a autora fixa formas e sentidos da indumentária, descontextualizando-os para, ela própria, resignificá-los contemporaneamente.

A mesma tendência metodológica encontramos na análise de imagens recorrentes em Pandora: Topographies of the Mask and Curiosity, de Mulvey (1992). As imagens seriam sucessivas expressões arquetípicas, como se houvesse um repertório original que ressurgiria reencarnado em figuras do cinema; "If Pandora is a prototype of the femme fatale, she found new life in the movies" (p. 68). 0 corpo feminino é visto como o receptáculo de estruturas psíquicas que produzem as diferenças entre o masculino e o feminino nos filmes:

I want to consider the image of the female body as a sign and try to analyse it in terms of space. That is, as topography, as a phantasmagoric projection which attempts to conceal, but in fact reproduces, the relation of the signifier the female body to psychic structures (p. 57).

Apesar dos problemas metodológicos e conceituais entre aqueles que reconhecem o papel da cultura material no entendimento da dinâmica das práticas e tensões sociais, há um consenso, com ênfases diferentes, na idéia de que o potencial do universo físico como documento aumenta conforme aumenta a possibilidade de contextualizá-lo. Produzir conhecimento sobre um artefato significa analisar suas características físicas, mas também colocá-lo em relação com os artefatos e espaços do seu entorno, levantar as experiências com artefatos semelhantes e igualmente os textos a eles relacionados (propagandas, periódicos, catálogos, etc). $\bigcirc$ artefato, como qualquer documento, deve ser compreendido na sua "intertextualidade", ou seja, dentro de um conjunto amplo de enunciados que dão sentido, valor, induzem e instrumentalizam as práticas.

Os cuidados metodológicos visam a impedir que se imponha aos artefatos em estudo uma classificação arbitrária, uma falsa compreensão de suas funções simbólicas e operacionais. Se aceitamos como premissa teórica que a estrutura social, suas relações de poder, hierarquias, formas de passagem e contato socialmente qualificado e, portanto, discriminatório, acontecem através do uso de "metáforas espaciais organizadas em pequena escala" (GOFFMANN apud ARDENER, 1997, p. 2), reconhecemos no microcosmo espacial - ou melhor, nas informações fragmentadas de alocações e usos de objetos que hoje nos chegam através dos documentos - uma forma válida de análise. A esta aproximação teórico-metodológica subjaz a idéia, aqui sempre recorrente, de que o espaço é constituído e percebido socialmente e que, de uma forma organicamente indissociável ele produz as práticas que o produziram. Nas palavras de Ardener (1997, p. 2), "behaviour and 
space are mutually dependent" (p. 2). No entanto, é justamente por causa de tal dependência que a análise exclusiva do contexto imediato do objeto pode não fornecer um enquadramento seguro para a definição dos valores e sentidos a ele atribuídos.

Se a cozinha de uma casa "burguesa" do início do século XX está morfologicamente próxima ao consultório médico, no que tange às matérias-primas utilizadas na confecção de móveis e objetos, funções instrumentalizadoras, atividades de processamento físico-químico, uso de tecnologia expressa na presença de equipamentos mecânicos, etc., o que explicaria seus valores opostos? A resposta imediata é a de que a cozinha é território feminino e doméstico, logo amador, e o consultório médico é masculino e profissional. Mas se são os objetos que constituem os gêneros, por que cabe aqui a inversão? Porque os significados são constituídos segundo a geografia global do sistema. Se as metáforas sociais estão na pequena escala dos objetos e ações rotineiras, estas são coerentes com o "mapa social".

A forma de controle da subjetividade do pesquisador deve se dar, então, não apenas através da contextualização dos objetos, mas da compreensão de como estes contextos são interdependentes das práticas cotidianas. Douglas demonstra que o contexto pode ser tão dinâmico quanto são as pessoas, e usa como exemplo o sentido dos lírios em funerais e jardins domésticos. A autora nota que o uso tradicional dos lírios em funerais foi, em determinada época, impedimento para seu uso em casa. No entanto, agora eles povoavam os jardins, viraram até moda. Baseando-se somente na informação de uso do objeto em contextos diferentes, poder-se-ia erroneamente concluir que houve uma aproximação entre a experiência de morte e vida. Na verdade, esta mudança de sentido está relacionada com o recuo do funeral como um evento genericamente importante, o que esvaziou a associação do lírio com a morte. Portanto, o sentido está ligado à cambialidade de sentidos mais amplos como a morte de alguém e seus rituais, ou seja, ao "[...] system of formal presentations between persons at lifecycle events. $[\ldots]$ The context for the meanings of the flowers is the context of persons" (DOUGLAS, 1994, p. 111 .

Para Riggins (1994), que produz uma etnografia do objeto, o controle da subjetividade se agrava quando não podemos observar os artefatos em situação ou não temos acesso aos seus usuários. Os artefatos, mesmo quando acessíveis, só podem ser alcançados através da fala de seus próprios usuários:

\begin{abstract}
A trained ethnographer would more likely have realized from the very outset of the research that one cannot begin to grasp the full significance of domestic objects when information is not elicited directly from members of a household through conversations and interviews. Much of the bricabrac in homes, travel souveniers, gifts, knicknacks, etc. symbolize relationships with people. Which objects are chosen for display and the styles of display provide interesting clues about interpersonal dynamics within households and beyond. Much of this knowledge cannot be acquired simply from observing objects (RIGGINS, 1994, p. 107).
\end{abstract}

Mesmo interessado na análise de artefatos, o que escapa a Riggins é, não a autonomia, mas a integridade documental dos artefatos. Na sua observação, parece que os artefatos são organizações insondáveis, que estão ali para suporte dos valores de seus usuários, sendo que o sentido só se faz presente quando nomeado pelo usuário. Por trás desta visão que privilegia o informante em detrimento do artefato, esconde-se uma outra noção problemática, 
logocêntrica, onde vigora uma correspondência direta entre o discurso do informante e o arranjo dos artefatos, sendo estes apenas um reflexo do enunciado lingüístico. $\bigcirc$ artefato não corresponde à unidade lingüística, ele tem potencial lingüístico, semiótico, pode ser usado na comunicação mas não pode ser equiparado, ou reduzido a ela. À função de comunicação é preciso sobrepor outras, próprias dos objetos, como tornar o modo de vida de seus usuários possível, operacional, o que muitas vezes dispensa qualquer palavra ou mesmo uma consciência sobre a interação do corpo com o artefato.

Se para o historiador da cultura material a possibilidade de descrever relações interpessoais é menor do que para o etnólogo (praticante de uma "microssociologia"), resta-lhe no entanto um amplo território a ser explorado, aquele em que os artefatos agem como forças ativas que constroem, constrangem ou estimulam as relações sociais. Estudar as formas de apropriação não invalida o interesse pela constituição das normas, pela idealização ou pelo projeto. Por outro lado, a figura do informante para o etnólogo pode ser substituída pelas narrativas que encontramos em romances, crônicas, artigos de jornal, manuais, etc.

Um exemplo de como a análise do artefato torna patente a ligação das práticas sociais com a produção e organização do mundo material pode ser apreciado nas reflexões de Sennett (1997, p. 273-277) sobre o significado do conforto no século XIX em seu livro Carne e Pedra. Sinalizando as hierarquias sociais ou facilitando a conversação, o conforto proporcionado pelo ato de sentar-se esteve sempre associado à mobilização do corpo para as práticas de sociabilidade, ou seja, sentar (ou o seu contrário, não poder sentar) era uma maneira de estabelecer contato com outras pessoas. No século XIX, a rotina do trabalho da indústria mostrou que no descanso controlado poderia haver um ganho significativo de produtividade. Começava a surgir uma nova maneira de se entender o conforto corporal. Projetadas em 1838 por um estofador francês, as poltronas de grandes proporções, com estofados macios e assentos de mola que envolviam o corpo num convite ao relaxamento, transformaram o ato de sentar-se em uma experiência individual. Mais do que isso, ao amortecer os sentidos e imobilizar o corpo, a poltrona alimenta a construção de uma nova noção de conforto associada à necessidade de reposição de forças através do alheamento. A relação do conforto com a individualidade está diretamente ligada ao sexo masculino. Sennett cita trabalhadores e escriturários que se orgulhavam de suas poltronas, onde recuperavam a energia perdida no trabalho. A associação da poltrona com o trabalho produtivo, na forma de antídoto, evidencia seu usuário por excelência. Não é por acaso que nos cartões de visita fotográficos do século XIX, o homem tem a prerrogativa do assento em detrimento da esposa que aparece em pé, atrás do marido. $\bigcirc$ conforto físico proporcionado pelas poltronas, cadeiras de escritório, bancos de carruagens e de vagões de trens vem acompanhado de uma indução à incomunicabilidade, diretamente associada a uma forma de individualidade que acreditamos ter no homem a sua matriz. A partir de tal perspectiva, a poltrona deixa de ser um simples reflexo das alterações nas relações sociais da modernidade. Ela faz parte ativa na indução dessas alterações. O deslocamento da análise de um quadro estritamente técnico, para aquele das mudanças de sociabilidades evidencia o potencial da noção de conforto como corporalidade no entendimento das relações de gênero. 
Apesar da rara existência de estudos nacionais que abordem diretamente gênero e cultura material, uma vasta produção bibliográfica sobre gênero abre todas as perspectivas para uma confluência das duas áreas.

Os balanços bibliográficos de Costa e Bruschini (1989), Samara (1997, 1996, 1989) e Silva (1991) mostram-nos que a preocupação acadêmica com problemas relacionados ao gênero iniciou-se nos estudos sobre a família, que floresceram originalmente nas áreas de antropologia e sociologia. Estes estudos, feitos durante a década de 60, estavam centrados nas formas de poder patriarcal e suas ligações com as dinâmicas sociais e raciais. A introdução do tema na historiografia se deu na década de 70, através de trabalhos de cunho demográfico que se ativeram às relações entre estrutura familiar e estrutura populacional. As mudanças de enfoque começaram a surgir na década de 80, não apenas com as abordagens vindas da história social, mas como fruto de tentativas, na sociologia, psicologia e antropologia social, de superar as simplificações da primeira geração de estudos "feministas". No entanto, ainda que brevemente, faz-se necessário lembrar que foram nestes estudos, desenvolvidos entre os anos 60 e 80 e voltados inclusive para países da América Latina, que o espaço doméstico despontou como cenário de interesse. Visto como o lugar de desenvolvimento da "cultura de opressão feminina", a sua constituição foi entendida a partir de fatores políticos e econômicos, aos quais somaram-se abordagens voltadas para o ideário "machista" na produção do "culto à domesticidade".

Uma forte vertente da historiografia sobre gênero caracteriza-se pelo abandono das imagens tradicionalmente vinculadas à mulher, os chamados estereótipos da figura feminina como dona-de-casa, mãe e complemento do marido ${ }^{12}$. Esta postura levou à valorização de documentos produzidos por mulheres e à leitura "enviesada" das fontes tradicionais da história, buscando-se as "fissuras" nos discursos normativos, por onde se poderia entrever a riqueza dos papéis sociais desempenhados pelas mulheres em uma sociedade dominada por homens. Temas e personagens variam muito. São mulheres da elite urbana, feministas, escravas, mulheres brancas, pobres, fazendeiras, mulheres judias [...], cujos papéis sociais são redefinidos sob a luz de problemas como o gerenciamento e a transferência de patrimônio familiar, a prostituição, o trabalho doméstico, o trabalho informal, o trabalho fabril, as atividades políticas e emancipatórias, as questões étnicas, a violência doméstica e amorosa, etc. As fontes incluem principalmente arquivos pessoais, periódicos, inventários, inquéritos policiais, leis e decretos, depoimentos entre outras (DIAS, 1984; GRAHAM, 1996; MALUF, 1995; SAMARA, 1996; SILVA, 1996; SOIHET, 1996; VAZ, 1995).

Em Barrocas Famílias, estudo dedicado à compreensão da vida familiar setecentista em Minas Gerais, Figueiredo (1997) reconhece que os novos caminhos abertos no campo da história das mentalidades possibilitaram revisões do modelo de família extensa. Conseqüentemente, questionou-se a imagem que a família extensiva sugeriria, ou seja, a de "uma sociedade acomodada e sem tensões". Nesta mesma direção, Samara (1989), em As Mulheres, o Poder e a Família (São Paulo, século XIX)'13, já demonstrara que o modelo de família extensa, pertinente a regiões do nordeste brasileiro, tipicamente rural e monocultor, foi impropriamente generalizado para todo o país a partir de leituras dos trabalhos de Gilberto Freyre.
12. "Até agora se tem admitido como incontestável, de maneira genérica e sem maiores distinções, a asserção de que a mulher brasileira viveu, no século XIX, mergulhada na atmosfera rígida e autoritária de uma família patriarcal (ainda não devidamente definida), alheia à vida nacional $\mathrm{e}$ aos seus problemas, mesmo quando educada e habitando as cidades; teria permanecido exclusivamente limitada à função de procriadora e às atividades domésticas, das quais só sairia para as devoções religiosas e os prazeres sociais. Estas afirmações têm servido de pano de fundo contra o qual são apreciadas as conquistas femininas do século $\mathrm{XX}$, fruto das lutas de algumas pioneiras das décadas de 10 e 20" (QUEIROZ, 1989, p. XI).

13. Ver da mesma autora Família e vida doméstica no Brasil: do engenho aos cafezais. (Estudos Cedhal; 10 - Nova Série). São Paulo: Humanitas, 1999. 
A associação da categoria gênero a variáveis sociais, étnicas e regionais permitiu que o impulso revisionista conduzisse historiadores a um mergulho nas novas estruturas de parentesco desvendadas através de fontes inéditas. Nelas teria sido possível perceber a existência de um universo heterogêneo de práticas que resistiram às imposições normativas que ambicionavam a institucionalização de um único padrão de vida conjugal (CORRÊA, 1994).

Problemas semelhantes foram apontados por Priore (1989), em $\bigcirc$ Corpo Feminino e o Amor: um Olhar, produção historiográfica sobre gênero que se aproxima dos objetos próprios da cultura material. Buscando apreender mudanças de sensibilidade, a análise contempla de certa forma o espaço doméstico, no entanto, ainda como cenário de idéias. Através de fontes como sermões, pastorais e manuais de confissão observou-se a difusão de um discurso normativo, emanado do poder institucionalizado da lgreja, que condenava o "mundo dos sentidos" e a "viveza de espírito", e que tentou impor-se durante todo o século XVIII. Ao mesmo tempo, em uma sociedade onde prevaleciam as uniões informais, a mulher vivia fora do casamento a experiência da sedução, "ao sabor do que chamamos o tempo do corpo amoroso". Segundo a autora, a experiência sensual não mediatizada conheceria seu momento de mudança durante o século XIX. Parte de um processo mais amplo de quebra dos laços comunitários e dos "grupos de vivência", as relações amorosas passariam a ser mediatizadas pelo "amor romântico". A aproximação física é substituída por um estado de alma; instaura-se o amor platônico e os fetiches encontram um campo fértil: "[...] [o rapaz] apaixonase, por exemplo, por uma moça que seria a dona de um pezinho que por sua vez seria o dono de um sapato encontrado" (p. 61 -66). Porém, se o "amor romântico" será mediatizado por um conjunto de regras que impõe o "afastamento dos corpos dos que se amam", estas formas de mediação, que não são formas desencarnadas e, portanto, certamente incluem o universo material, não são exploradas em suas análises literárias.

A dissociação do universo material das relações sociais certamente tem uma de suas causas na forma ainda pouco contumaz com que o historiador se debruça sobre as fontes tridimensionais e iconográficas. $\bigcirc$ projeto editorial dos volumes da História da Vida Privada no Brasil, coleção dirigida por Fernando Novais (1997-98), mostra que, apesar do investimento na busca de documentos não-textuais, ainda há dificuldade em utilizá-los. Nestes volumes, uma extensa e rica pesquisa de objetos e imagens ligados à cultura material, associada à formação da intimidade, privacidade e domesticidade brasileira, apresenta-se dissociada das questões desenvolvidas em cada capítulo. Assim, a riqueza documental que o projeto produziu, em vez de estimular os autores a absorvê-la como matéria-prima de suas reflexões, acabou por constrangê-los a comentários atomizados nas legendas. Tal descompasso entre problema histórico e pesquisa documental levou autores sensíveis à documentação material como Maluf, Algranti, Mott e Priore ao trato equivocado de um material que poderia ter enriquecido as análises que desenvolveram.

Na coleção citada, um exemplo do uso ilustrativo das fontes materiais pode ser observado no capítulo Ritos da Vida Privada de Priore (1997). Para tratar das formas de distinção social almejadas pelos homens da elite neste período, a autora anuncia logo no início da primeira parte do capítulo que suas fontes serão o livro borrador e o lunário de Antônio Gomes Fernão Castelo Branco, senhor-de- engenho na Bahia de 1748. No entanto, nas margens do texto vemos 
retratos em pinturas a óleo, instrumentos de castigo de escravos, um bidê, uma cadeirinha de arruar. Sobre esta última demonstrou Barbuy (1991) seu potencial para o entendimento das formas de distinção social no artigo Entre Liteiras e Cadeirinhas. A autora dá destaque a uma cadeirinha de arruar utilizada na cidade de São Paulo entre os séculos XVIII e XIX ${ }^{14}$, na qual o apuro estético intenso nas suas partes externas servia para identificar seu proprietário e outorgar-lhe o devido status. No entanto, mais próxima à concepção de um móvel doméstico do que à de um veículo urbano, ao mesmo tempo em que se exibia publicamente, a cadeirinha de arruar mantinha a privacidade de seu proprietário ao circunscrever na paisagem externa um espaço formal e normativo próprio da sala de visitas.

No capítulo Famílias e Vida Doméstica, Algranti (1997) analisa as mudanças ocorridas no modo de vida doméstico na Colônia com o intuito de descrever os indícios materiais do surgimento da intimidade, encontrados nos inventários e descrições de viajantes. O fio condutor de sua reflexão baseia-se não nas composições familiares, que variavam muito e não permitiam uma abordagem panorâmica do fenômeno, mas no espaço do domicílio, identificado como o local de uma possível intimidade. Pautando-se na fisicalidade do cotidiano doméstico, a autora conjuga descrições de cômodos, objetos de decoração e uso rotineiro, programas residenciais para circunscrever as formas de sociabilidade do período colonial. No entanto, mesmo neste caso em que a análise se posiciona claramente na perspectiva da cultura material, a pesquisa iconográfica se justapõe ao texto, como uma outra narrativa, com funções editoriais de conforto (descanso da leitura) e sedução do leitor.

Outro exemplo, no mesmo volume, de autores que se orientaram para o uso de dados da cultura material encontra-se no capítulo Recônditos do Mundo Feminino, de Maluf e Mott (1998). A análise dos embates e contradições nos discursos sobre os "lugares" da mulher, enriquecida com descrições sobre o trabalho doméstico diante de novidades como fogões a gás, equipamentos de banheiro e aspiradores de pó, contribui para elucidar os dilemas e as demandas sociais e pessoais perante os quais as mulheres estavam colocadas. Às margens do texto estão imagens de espartilhos, medicamentos para os "nervos", cortes de cabelo, moda, móveis, porém sem informar sobre a sua importância no processo em questão, o que acaba transformando tais fenômenos em simples curiosidades, ou seja, naquilo que Rede (1996, p. 267) apontou como elementos periféricos, logo, não geradores de realidades.

Tomemos como exemplo dos problemas inerentes à desarticulação entre pesquisa e fontes materiais presentes em projetos editoriais de grande porte ${ }^{15} \mathrm{O}$ confronto de uma imagem e seu comentário. A imagem é a de uma jovem mulher ao telefone e ilustra o trecho em que Maluf e Mott (1998) comentam as novas aspirações e possibilidades de trabalho feminino no início do século XX. A mulher entrou no mercado de trabalho exercendo profissões consideradas femininas, entre elas a de telefonista. A recuperação pitoresca das indagações da época sobre a natureza "tagarela e bisbilhoteira" das mulheres e do tremendo sucesso do aparelho telefônico junto a elas vem acompanhada de um argumento que só parcialmente poderia explicar tal fenômeno: "[...] menos por causa da tagarelice, será que a profissão não acabou se tornando adequada às mulheres pelo fato de trabalharem em local fechado, sem se expor aos olhares do público?" (p. 404). Certamente, o isolamento da cabine e das salas de trabalho, a restrição do contato direto, a facilidade de segregação do sexo oposto foram motivos fundamentais. $\bigcirc$ que nos
14. Hoje pertencente ao acervo do Museu Paulista da USP.

15. Procedimento que, fora do âmbito acadêmico, disseminou-se nos trabalhos sobre "memória" empresarial conduzidos pelos departamentos de marketing. 
chama a atenção, no entanto, é que a figura feminina reproduzida da revista $A$ Cigarra (1918) informa-nos em outra direção. Observando a imagem notamos que não se trata da representação de um ambiente de trabalho, ao contrário, ela evoca o espaço da casa ao apresentar uma mulher com vestido decotado, écharpe, sapatos de salto alto, sentada em cadeira almofadada com braços em volutas, tendo à sua frente um cachorro que parece acompanhar seus movimentos ao telefone e que está presente para reforçar a domesticidade do ambiente sugerido. Mais do que resultado de um autoritarismo vigilante e cerceador da sociedade, o exemplo nos mostra como a construção cultural da "natureza" feminina determina o seu caminho dentro da modernidade tecnológica. A imagem e o comentário da própria revista fornecem indícios para entendermos como as "aptidões", reconhecidamente femininas, de mediadora e conciliadora das relações entre os homens, de alguém treinada para saber ouvir e conversar, serviram para introduzila com êxito em determinadas áreas criadas pelas novas tecnologias, como aquela dos meios de comunicação.

A propósito, Schwartz (1996), em estudo já comentado sobre o uso sexuado dos aparelhos de surdez, demonstrou num outro contexto as especificidades culturais do ouvir feminino. Tais aparelhos só foram incorporados pelas mulheres quando suficientemente desenvolvidos a ponto de serem camuflados e capazes de distinguir variações tonais, importantes para o ouvido refinado da mulher. A deficência auditiva, mais do que um problema prático, significava perda de feminilidade, já que a conversação era uma arte dominada pelas mulheres, na qual a boa audição era fundamental para acompanhar todos os sentidos contidos não somente nas alterações de intensidade e ritmo da fala, mas na observação das expressões faciais, possível somente quando o interlocutor está frontalmente posicionado.

A análise da moda empreendida pioneiramente em 1951 por Mello e Souza (1987), O Espírito das Roupas: a Moda no Século Dezenove, aproximase mais do universo de nosso interesse - aquele das relações entre indumentária feminina e masculina vistas segundo seus atributos físicos como formas, cores, tecidos e dentro de um quadro de problemas que inclui estratégias materiais de negação ou afirmação do universo do trabalho, da sedução, da domesticidade e da mobilidade social. Almeida (1995), em seu comentário crítico Indumentária e Moda: Seleção Bibliográfica em Português, pondera que apesar de adotar um referencial teórico que conduz a autora a uma compreensão da indumentária como expressão material passiva de fenômenos sociais, a análise afasta-se das premissas iniciais apresentando o vestuário "como um verdadeiro dispositivo material que conforma os movimentos físicos do indivíduo, mobilizando o corpo na efetivação concreta das relações sociais" (p. 276). Tal percepção surge, por exemplo, na interpretação das modificações das saias entre os anos de 1850-80, quando fica claro que a moda não apenas reflete as transformações sociais mas pode opor-se a elas. No presente exemplo, a indumentária mostra-se como um instrumento de segregação entre os sexos em uma sociedade onde a aproximação social e sexual conhece novas oportunidades:

Constatamos que a saia-balão e a crinolina atingem seu volume máximo, tolhendo a capacidade de movimento de suas usuárias, num momento em que a tecnologia do transporte - é a época dos trens - ganha um forte impulso; em seguida, abandonada a preocupação com os volumes, surgem as caudas longas que têm o mesmo efeito de não facilitar a movimentação; e mesmo uma mudança mais significativa como o 
aparecimento, nos anos de 1880, das saias justas, com inúmeros adereços, que dificultam até mesmo o ato de sentar (ALMEIDA, 1995, p. 276).

Aponta também nesta direção o estudo de Schpun (1999), Beleza em Jogo. Cultura Física e Comportamento em São Paulo dos Anos 20, que analisa o corpo e os acessórios femininos como um instrumento de distinção social, logo, como um tipo de artefato culturalmente produzido para definir o padrão de "beleza" e, naturalmente, suas decorrentes variações e formas desviantes.

Outro campo cuja produção tangencia os objetos circunscritos por este ensaio é o da arquitetura. $\bigcirc$ crescente interesse pelo patrimônio colonial, a criatividade e a projeção internacional que alcançaram as experiências arquitetônicas nacionais e a reconhecida vinculação das transformações da moradia com o processo de urbanização são alguns dos fatores que levaram arquitetos e historiadores da arquitetura a se empenhar na montagem das tipologias das habitações brasileiras. Estes estudos analisam o espaço físico de vivência familiar e de constituição da interioridade burguesa, mostrando-nos, ao longo das mudanças tipológicas, os determinantes legais, a sobrevivência de heranças coloniais, de adaptações e transições para o "morar à francesa" protagonizado idealmente pelo palacete. Além do mérito que possuem para a área na qual atuam, estas pesquisas fornecem balizas importantes a partir das quais se pode constituir a reflexão sobre as práticas sexuadas domésticas. A análise das estruturas da moradia brasileira instrumentaliza o campo específico das relações entre gênero e artefatos ao demonstrar os objetivos projetuais e os resultados efetivamente alcançados daquilo que constituiu o ideário ordenador e cosmopolita burguês. Por outro lado, a necessidade de compreender o processo de especialização da habitação burguesa ultrapassou a descrição estrutural do espaço, chegando-se à recuperação de informações sobre o modo de vida nas casas através de documentos fotográficos e descrições orais e textuais levantadas em inventários, correspondências ou periódicos (BRUNO, 1977; CARVALHO, 1996; FABRIS, 1987; HOMEM, 1996; LEMOS, 1999a, 1999b, 1989, 1978; SAIA, 1972).

O estudo de Homem (1996), O Palacete Paulistano e Outras Formas Urbanas de Morar da Elite Cafeeira, parte, como Gilda de Mello e Souza, de uma premissa que, levada às últimas conseqüências, promoveria o esvaziamento da natureza física das relações sociais - o surgimento do palacete estaria determinado por fatores alheios às práticas espaciais:

Porém, para que se construísse um novo espaço, foi necessário que se alterasse primeiro o modo de vida, o qual, no entanto, ocorreria de forma independente do espaço" ( $p$. 16) ou, "Para que o espaço doméstico se alterasse, foi preciso mudar primeiro o nível econômico e o modo de vida do proprietário e da família e, com eles, os programas das necessidades (HOMEM, 1996, p. 47).

Conclui-se que a criação do "novo espaço" é produto de relações sociais dele independentes. Felizmente, a camisa-de-força da premissa teórica não impediu que a autora demonstrasse ricamente como sobrados e chácaras coloniais foram gradativamente sofrendo alterações que os conduziram aos padrões de refinamento propagandeados pelo modo de vida burguês. $\bigcirc$ programa de necessidades realizado idealisticamente no palacete paulistano, sendo ele mesmo já uma certa seleção dos modelos importados da França, vinha sofrendo fusões com os modelos tradicionais. As "casas abastadas" e estruturalmente mistas acomodavam em seus interiores objetos de decoração e práticas que apontavam 
16. Tipo de mesa comumente presente na sala de jantar, utilizada até hoje, que pode ser aberta ao meio para receber uma ou duas tábuas que aumentam o seu tamanho.

17. As variáveis gênero e espaço se sobredeterminam, ou seja, se o gênero marca o espaço, como temos visto até agora, também o espaço marca o gênero, quando os sentidos sexuados dos espaços migram para a performance social. Situações desse tipo são observadas na literatura brasileira. É o caso do romance $S e$ nhora, escrito em 1875 por José de Alencar (1997, p. 27). Neste caso, a masculinização da personagem feminina foi possibilitada pelo deslocamento da ação para o espaço do gabinete onde, então, a moça de 18 anos conversa sobre a administração de sua fortuna em pé de igualdade com o seu tutor. na direção do modo de vida burguês. Portanto, o que parece justificar, na premissa, a desconexão entre o espaço e o modo de vida é uma visão demasiadamente rígida da aplicação do modelo espacial do palacete e a desconsideração de que um espaço se constitui também com os artefatos a ele associados. Por outro lado, seu estudo dos palacetes paulistanos contribui para flexibilizar os esquemas binários levados ao extremo por pesquisadores como Diana Wall, ou as análises pesadamente sexistas que excluem da história da mulher a presença masculina, como vimos em Arpad e Gordon. Aqui a autora mostra-nos como no espaço doméstico do palacete a representação da sociabilidade masculina, pública e privada, tem lugar preponderante, expressa no grande número de ambientes da casa a ela voltados:

Apesar de a casa destinar-se ao reino da mulher, o espaço maior foi literalmente dedicado ao homem. Pela primeira vez, ela teve uma sala para si mesma, a denominada sala da senhora, mas o marido ganhou o bilhar, o fumoir, a biblioteca e até a sala de armas, além de ter preservado o seu gabinete, sempre na frente da casa, com entrada independente (HOMEM, 1996, p. 248).

O modo de evolução da planta da casa colonial para o palacete, no caso paulistano, mostra-nos como este ambiente conheceu variações da planta ideal, ao manter, por exemplo, a posição da sala de jantar em local intermediário às áreas de repouso e serviço, resguardando o hábito de ocupar esse espaço para vivências mais íntimas e, portanto, informais, o que não significou o seu aparelhamento para tal finalidade ou a exclusão das funções públicas e masculinas a ela associadas. A maleabilidade dos espaços no momento da ação nos mostra que a produção de sentidos é muito mais dinâmica do que uma análise exclusivamente espacial ou tipológica de artefatos poderia indicar.

Não sendo falsas, porém, as associações mulher/interior/privado em oposição àquelas homem/exterior/público ocultam situações ambíguas ou complementares, como a atuação da mulher no cerimonial da sala de visitas, ou sua presença intersticial no ritual de alimentação comandado pelo homem na sala de jantar. Retomando as preocupações de Douglas (1994), agora nas palavras de Shirley Ardener - "space defines the people in it", mas reciprocamente "people define space" $(1997$, p. 3) - percebemos como um espaço projetado e efetivamente utilizado para determinadas funções públicas fortemente ritualizadas pode, com a mudança do tipo de atividade e em situação mais informal assumir sentidos diferentes mesmo que este espaço esteja sinalizado para o seu fim primeiro. Vários manuais de orientação doméstica nos mostram que a sala de jantar, com a presença da "mesa elástica"16 ou de equipamentos de costura, servia adequadamente para as mulheres da casa passarem a roupa ou costurarem. Certamente, imaginamos que na casa existam espaços tão fortemente "sacramentados" com as práticas para as quais foram designados que dificilmente poderíamos imaginar uma subversão cotidiana aceitável, como a sala-oratório tradicionalmente presente antes da propagação do modelo de morar burguês. Mas este não parece ter sido o caso da sala de jantar paulistana ${ }^{17}$.

Os esquemas binários, assim como a busca por estruturas universais nos estudos culturais comparativos, não podem fazer submergir a multiplicidade de situações que diferentes mulheres enfrentam na sociedade em que vivem, especialmente quando se trata de pensar nas formações ocidentais complexas. As práticas femininas diferem conforme a condição patrimonial envolvida, a idade 
(criança ou moça), a expectativa de estender laços políticos e econômicos através do casamento, etc. Dias (1 984), em Quotidiano e Poder em São Paulo no Século XIX, traça um quadro de vida bastante diferenciado para aquelas mulheres que, pobres e chefes de família, utilizam "masculinamente" o espaço urbano, onde, para elas, a questão principal não era estar ou não reclusa em casa, mas conseguir, por exemplo, burlar o fisco que controlava as fronteiras entre o perímetro urbano e as áreas rurais de onde elas traziam mantimentos para consumo e venda. Vê-se aqui como as distinções de gênero e suas articulações com o espaço estão também diretamente vinculadas à estrutura familiar e à situação de cada segmento social.

A sintonia entre práticas, espaços, indumentária, normas de conduta e artefatos é finamente explorada nos estudos com base arqueológica de Lima (1995, 1997, 1999). No Brasil, é no campo da arqueologia, obrigada a desenvolver um apurado conhecimento técnico das fontes materiais, criando com elas uma intimidade desconhecida pelo historiador, que encontramos uma forte articulação entre as fontes relacionadas à cultura material e as problemáticas históricas. A implantação do modo de vida burguês no Rio de Janeiro é estudada a partir da "tralha doméstica" obtida nas escavações de habitações do séc. XIX. O estudo que aqui nos interessa ressaltar é Chá e Simpatia: uma Estratégia de Gênero no Rio de Janeiro Oitocentista, talvez o único, ao lado do pioneiro Espírito das Roupas, que no contexto nacional constrói claramente uma intersecção entre gênero e cultura material. Os padrões de decoração dos fragmentos de louças inglesas (vestígios predominantes no universo de documentos encontrados), confrontados com informações obtidas em manuais de etiqueta e na literatura de ficção, permitiram demonstrar como os artefatos da casa, mobilizados na cerimônia do chá, viabilizaram as disputas de poder entre homens e mulheres, estas últimas sustentando estratégias de domínio em espaços francamente patriarcais. A interpretação de Tania A. Lima quanto às diferenças estilísticas entre os aparelhos de chá e de jantar opõe-se frontalmente à de Diane Wall. Para esta última, como vimos, as diferenças são expressões de funções femininas também diferentes - no ritual do jantar a mulher representa a nutrição e o esteio moral da família; no ritual do chá ela exibe e negocia o status social da família. Para a arqueóloga do Museu Nacional, as mudanças nos rituais do chá desembocaram na constituição deste cerimonial como um fenômeno marcadamente feminino e, como tal, diferenciase formalmente do ritual do jantar, comandado pelo homem. Tal diferenciação está nas oposições estilísticas entre os aparelhos de cada cerimonial, nos locais onde eles se realizam, nos trajes utilizados, na forma de absorção dos alimentos, no uso diferenciado dos talheres e nas regras de etiqueta e performance corporal exigidos para cada um dos eventos.

As intersecções de natureza dinâmica, portanto mutáveis, que pode haver entre as conotações femininas e masculinas nos espaços da casa, bem como entre as situações públicas e privadas nos levam a pensar na existência dessa flexibilidade nas habitações coloniais brasileiras extremamente rígidas nas suas dicotomias sexuais e sociais. Observando os inúmeros trechos de viajantes e crônicas coletados por Bruno (1998, 1999; ACAYABA, 2001), notamos que as casas, até o séc. XVIII, que eram rigorosamente pobres em mobiliário, possuindo quando muito mesa, bancos, esteiras e baús, tinham, não raro, no quarto de dormir do proprietário ou no de hóspedes, uma cama ricamente ornamentada, por vezes com a presença de dourados, solidamente constituída e paramentada com colchas de rendas e lençóis alvíssimos, de tecido de ótima qualidade. Não 
deixa de ser instigante imaginar que nas casas conhecidas por suas alcovas sem janelas, incrustadas no meio do corpo doméstico, segregadas das áreas de presença social externa pudesse estar presente talvez o único móvel rico da casa, indício de exposição social mais alargada do que poderíamos pressupor.

problema da decoração doméstica parece ser um dos mais promissores para o entendimento do caráter sexuado das funções sociais. As questões sugeridas a partir da coletânea The Arts and the American Home, editada por Marling e Foy, nos levam a refletir sobre a sua relevância no contexto brasileiro. Na análise de Costa (1983), Ordem Médica e Norma Familiar, sobre a metamorfose da família tradicional em família nuclear burguesa regida por padrões de conduta produzidos pela nova medicina sanitária, percebemos as decorrências do raciocínio pautado sobre a fixidez das oposições gênero/sentidos. Se a casa é entendida como território feminino, o seu enriquecimento em itens de conforto e decoração só pode ser a expressão do aumento da autonomia e poder da mulher após as transformações da estrutura patriarcal:

\begin{abstract}
$\bigcirc$ estar da família colonial, portanto, regulava-se pela distinção social do papel do homem e da mulher e pela natureza das atividades domésticas. $\bigcirc$ homem, a quem era permitido um maior contato com o mundo, com a sociabilidade, permanecia menos tempo em casa. Os cuidados da residência eram entregues à mulher que, entretanto, não podia imprimir aos aposentos a marca de suas necessidades. Esta posição de dependência diante do marido refletia-se na organização dos interiores. Como veremos, - interior da casa colonial era desprovido da maioria dos objetos que tornam um ambiente agradável e propício ao repouso. Ao homem pouco interessava estruturar um arranjo doméstico voltado para o aproveitamento do tempo livre, já que podia e devia usufruir este tempo na rua, conforme o hábito cultural. A mulher, embora pudesse eventualmente querer organizar o domicílio de uma outra maneira, não poderia fazê-lo, pois não dispunha de iniciativa pessoal nem de autonomia econômica para tanto. Além do que, comprimida pela estrutura funcional da residência, era obrigada a dispensar essas ocupações supérfluas e ocupar o tempo ocioso nos trabalhos caseiros (COSTA, 1983, p. 82-83).
\end{abstract}

reconhecimento da casa como território seguro e confiável, tendo na mulher o seu símbolo, sem dúvida implicou a valorização da condição social feminina. $\bigcirc$ autor, ao evidenciar a ligação do médico com a estrutura familiar, mostra-nos como a esposa assume o papel de mantenedora da saúde de seus filhos e do marido, função associada à formação de seus membros como cidadãos. No entanto, funções de mediadora, gerenciadora ou mesmo educadora, que implicam alto grau de controle espacial, não significam necessariamente poder ou domínio espacial em detrimento da presença masculina. Cremos que o incremento doméstico seja resultante de divisões sociais e espaciais que vão além daquelas que reestruturaram a família. Tais mudanças, que resultaram na delimitação da casa como seara do privado, compeliram o homem a nela constituir o seu espaço individual, daí, portanto, o seu enriquecimento, já que o sistema nunca deixou de ser androcêntrico. $\bigcirc$ autor trata como intercambiáveis ação e ação consciente, quando, como vimos anteriormente, ao confrontarmos as hipóteses de Wall com as considerações de Gilchrist, a ação tem uma natureza estruturalmente determinante, reproduzindo na maioria das vezes o sistema.

fenômeno de esvaziamento das funções produtivas domésticas apontadas por Marling no contexto americano ainda não foi analisado no contexto paulistano, onde encontraríamos paralelos instigantes. Aqui a passagem do século XIX para o XX marca um período de transição lenta mas também inexorável para as famílias, especialmente aquelas que se estruturaram de forma 
nuclear (padrão predominante em São Paulo conforme SAMARA, 1999). Estudos nessa direção apontariam as peculiaridades paulistanas na adoção dos estilos e formas de decoração intensamente aplicadas na Europa e Estados Unidos. Os manuais de orientação e os anúncios publicitários são fontes disponíveis e fundamentais para responder a questões desse tipo. Nelas observamos a preocupação com a entrada de dinheiro e a sua distribuição parcimoniosa para o cumprimento de toda a rotina doméstica, o que demonstra este deslocamento de funções, onde a reprodução familiar é, cada vez mais, garantida pela forma abstrata de trabalho expressa no salário mensal. Em São Paulo, este momento de inflexão parece ter-se dado surpreendentemente nas famílias nucleares dos estratos médios, que mais cedo do que as famílias da elite viram suas formas autônomas de sobrevivência segregadas pelos serviços urbanos estatais e privados, que se fortaleciam e tornavam cada casa uma célula deles dependente. A idéia de que o padrão de comportamento daș elites se espraia para os estratos inferiores deve ser neste caso relativizada. E verdade que os artefatos e formas de arranjo são inaugurados nos estratos mais abastados e divulgados em lojas, revistas, catálogos e manuais, transformando-os em modelos para os demais grupos sociais. No entanto, estes modelos, reproduzidos com alterações de técnicas, matérias-primas, acabamentos e simplificações de padronagens e arranjos, são utilizados pelos estratos médios não mais como formas predominantes de exibição social, mas para constituir a casa como um local exclusivo de refúgio. A adoção de ambientes simplificados e fortemente coerentes em termos cromáticos e estilísticos - pelas classes abastadas européias e americanas após 1890 - parece não ter influenciado o gosto das elites paulistanas, que permaneceram apegadas aos padrões de acumulação e ordenação instituídos pelo ecletismo. As mudanças no âmbito internacional, no entanto, vão seduzir os estratos médios nas primeiras décadas do século XX através de pequenas dicas de decoração, conselhos práticos e econômicos para o arranjo da casa. Os novos parâmetros de decoração são aqui apropriados por estratos sociais diferentes e com sentidos sociais também diversos daqueles onde tiveram origem. As elites paulistanas continuam investindo no ecletismo como forma de distinção social, já que a vulgarização dos ambientes com alta densidade de objetos, a banalização proporcionada pela industrialização e o barateamento de artefatos domésticos não tiveram em nosso território o mesmo impacto que no exterior. Os argumentos que convenceram as elites fora do país vão ser aqui empregados como estratégia de venda de mobiliário mais barato e simplificado para os estratos médios da população, onde se busca, por exemplo, criar laços entre simplificação, industrialização e modernidade.

A função psicossocial que a casa assume, viabilizada pelos objetos domésticos, compete em importância estrutural relativa à problemática do gênero com aquela de exibição social. As classes endinheiradas são as que melhor puderam criar e garantir espaços de privacidade já que a forma mais bem acabada de promoção da interioridade está na especialização dos espaços, cujo modelo é o palacete. No entanto, as funções culturais, educacionais, sociais e políticas que as famílias de elite mantiveram não constituíram na sua forma mais cristalina, como teria ocorrido nos estratos médios, aquilo que seria o modelo ideal contemporâneo de funcionamento da família - um local de reprodução do sistema através da estabilização das estruturas psíquicas dos indivíduos. 
18. "Gender, like class, is defined here as an aspect of social structure which is socially created and historically specific, in contrast with the categories of male and female sex wich are fixed and biologically determined"(GILCHRIST, 1994, p. 1).
Conclusão

Constituídas originalmente em áreas de interesse acadêmico diverso, gênero e cultura material aproximaram-se significativamente nas últimas duas décadas, a ponto de constituírem um campo vasto, ainda pouco explorado, de interesses comuns. Várias são as plataformas projetadas por bibliografias que, se por vezes não tratam diretamente de gênero, informam o contexto material onde a categoria gênero é construída. Trata-se de estudos sobre a formação da família e do espaço doméstico, incluindo aqui desde a estrutura da moradia até o uso prático e simbólico de seus artefatos.

A aproximação das duas categorias de análise fizeram migrar para este novo campo do conhecimento problemas teóricos próprios de suas áreas de origem, como a suposta autonomia dos universos femininos e masculinos, a fetichização do objeto, seu tratamento reflexivo, a busca por estruturas universalizantes, entre outros já mencionados. Frutos da própria história do desenvolvimento de tais disciplinas, da dissolução desses nós epistemológicos depende o avanço na compreensão dos fenômenos de gênero na perspectiva da cultura material.

O entendimento do gênero ${ }^{18}$ como uma categoria de análise tem duas implicações fundamentais. A primeira delas está em considerála, assim como a categoria "classe social", parte ativa na formação, funcionamento e transformação da sociedade. A segunda está em não tratá-la como categoria isolada e autônoma, seja internamente, constituindo histórias das mulheres independentemente daquela dos homens, seja externamente, com a produção de histórias de gênero desvinculadas das demais variáveis que respondem pela dinâmica social.

Hoje fica cada vez mais evidente que não é possível entender as estruturas sociais sem considerá-las estruturas sexualizadas. Tal reconhecimento implica outro, ou seja, reconhecer a importância da experiência cotidiana, lugar onde moldam-se as personalidades, disciplinam-se os corpos, forma-se a percepção, geram-se os sentimentos de familiaridade, os hábitos, etc. Como seria possível entender o universo das práticas diárias sem considerar aquilo que as viabiliza, isto é, o mundo material? O tratamento do espaço doméstico como constitutivo de um campo operatório onde a vida efetivamente acontece, e com ela a atribuição de gênero, certamente lançará luzes sobre os processos culturais de naturalização das diferenças entre homens e mulheres, hoje revigorados pela força ideológica das "descobertas" das biociências, divulgadas constantemente na mídia impressa e eletrônica não-especializada, e que deixam submersas as formas de poder que a partir da naturalização são praticadas e justificadas.

\section{REFERÊNCIAS}

ACAYABA, Marlene Milan (Coord.); GUERRA, José Wilton; SIMÕES, Renata da Silva; ZERON, Carlos Alberto (Org.). Equipamentos, usos e costumes da casa brasileira. São Paulo: Museu da Casa Brasileira, Imesp, Edusp, 2001, 4 vols.

ALGRANTI, Leila Mezan. Famílias e vida doméstica. In: MELLO e SOUZA, Laura de (Org.). História da vida privada no Brasil: cotidiano e vida privada na América Portuguesa. São Paulo: Companhia das Letras, 1997.v. 1, p. 83-154. 
ALMEIDA, Adilson José de. Indumentária e moda: seleção bibliográfica em português. Anais do Museu Paulista, São Paulo, v. 3 p. 251-296, jan./dez. 1995.

ALTMAN, Irwin;WERNER, Carol M. Home environments: human behavior and environment. New York: Plenum Press, 1985.

ARDENER, Shirley. Ground Rules and Social Maps for Women:an Introduction. In:ARDENER, Shirley (Ed.). Women and space. Ground rules and social maps. Oxford: Berg, 1997. p. 1-30.

ARPAD, Susan S."Pretty Much to Suit Ourselves": Midwestern Women Naming Experience Through Domestic Arts.P.11-26.In:MOTZ, Marilyn Ferris;BROWNE, Pat.Making the american home. MiddleClass Women \& Domestic Material Culture 1840-1940. Bowling Green/Ohio: Bowling Green State University Popular Press, 1988. p. 11-26

ASH,Juliet.The Tie:Presence and Absence.In:KIRKHAM,Pat.(Ed.). The gendered object. Manchester: Manchester University Press, 1996. p. 162-71.

ATTFIELD, Judy. Barbie and Action Man:Adult Toys for Girls and Boys, 1953-93. In: KIRKHAM, Pat. (Ed.). The gendered object. Manchester: Manchester University Press, 1996. p. 80-89.

AYRES, William S. Pictures in the American Home, 1880-1930. In: FOY, Jessica H.; MARLING, Karal Ann. The arts and the american bome, 1890-1930. Knoxville:The University of Tennessee Press, 1994. p. 149-164.

BARBUY, Heloisa. Entre Liteiras e Cadeirinhas. In: MENESES, Ulpiano T. Bezerra de (Org.). Como explorar um museu bistórico. São Paulo: Museu Paulista, 1991. p. 19-21.

BERNARDES, Maria Thereza Caiuby Crescenti.Mulberes de ontem? Rio de Janeiro - Século XIX. São Paulo:T.A. Queiroz, 1989.

BOXSHALL, Jan. Good housekeeping. Every home should have one. London: Ebury Press Random House, 1997.

BROOKS, Bradley. Clarity, Contrast, and Simplicity: Changes in American Interiors, 1880-1930. In: FOY,Jessica H.; MARLING, Karal Ann. The arts and the american bome, 1890-1930. Knoxville:The University of Tennessee Press, 1994. p. 14-43.

BRUNO,Ernani da Silva;JULIÃO, Maria de Lourdes (Org.).Aspectos gerais. In:FICHÁRIO do equipamento e dos costumes da casa brasileira. São Paulo: Museu da Casa Brasileira, 1999. 1 v.(ms)

BRUNO,Ernani da Silva;JULIÃO, Maria de Lourdes (Org.). Decoração.In:FICHÁRIO do equipamento e dos costumes da casa brasileira. São Paulo: Museu da Casa Brasileira, 1996. 2 v. (ms)

BRUNO, Ernani da Silva;JULIÃO, Maria de Lourdes (Org.). Interiores de residências (1807-1898). In: FICHÁRIO do equipamento e dos costumes da casa brasileira. São Paulo: Museu da Casa Brasileira, $1998.1 \mathrm{v} .(\mathrm{ms})$

BRUNO, Ernani da Silva;JULIÃO, Maria de Lourdes (Org.). Mobiliário. In:FICHÁRIO do equipamento e dos costumes da casa brasileira. São Paulo: Museu da Casa Brasileira, 1998. 7 v. (ms) 
BUCKLEY, Cheryl. Children's Clothes: Design and Promotion.In:KIRKHAM,Pat.(Ed.). The gendered object. Manchester: Manchester University Press, 1996. p. 103-111.

CARVALHO, Maria Cristina Wolff de. Bem-morar em São Paulo, 1880-1910: Ramos de Azevedo e os modelos europeus. Anais do Museu Paulista, São Paulo, v. 4, p. 165-200, jan./dez. 1996.

CLARK, Emily. Own Your Own Home. S. E. Gross, the Great Domestic Promoter. In: THOMPSON, Eleanor McD. The american bome. Material culture, domestic space, and family life. (A Winterthur Book). Winterthur: Henry Francis du Pont Winterthur Museum, 1998. p. 135-153.

COLOMINA, Beatriz (Ed.). Sexuality \& space. Princeton: Princeton Architectural Press, 1992.

COSTA, Albertina de Oliveira; BRUSCHINI, Cristina. Nem heroínas, nem vítimas. In: COSTA, Albertina de Oliveira Costa; BRUSCHINI, Cristina (Org.). Rebeldia e submissão: estudos sobre condição feminina. São Paulo:Vértice / Editora Revista dos Tribunais / Fundação Carlos Chagas, 1989. p. 9-15.

COSTA, Jurandir Freire. Ordem médica e norma familiar. $2^{\circledR}$ ed. Rio de Janeiro: Graal, 1983.

D'INCAO, Maria Ângela. O amor romântico e a família burguesa. In: D'INCAO, Maria Ângela (Org.). Amor e família no Brasil. São Paulo: Contexto, 1989. p. 57-71.

DIAS, Maria Odila Leite da Silva. Quotidiano e poder em São Paulo no século XIX. São Paulo: Brasiliense, 1984.

DOUGLAS, Mary.The Genuine Article. In: RIGGINS, Stephen Harold (Ed.). The socialness of things: essays on the socio-semiotics of objects. Berlim: New York: Mouton de Gruyter, 1994. p. 9-22.

FABRIS,Annateresa (Org.). Ecletismo na arquitetura brasileira. São Paulo: Nobel, 1987.

FIGUEIREDO, Luciano Raposo de Almeida. Barrocas famílias: vida familiar em Minas Gerais no século XVIII. São Paulo: Hucitec, 1997.

GILCHRIST, Roberta. Gender and material culture. The archaeology of religious women. London: Routledge, 1997.

GORDON, Beverly. Cozy, Charming, and Artistic: Stitching Together the American Home. In: FOY, Jessica H.; MARLING, Karal Ann. The arts and the american bome 1890-1930. Knoxville: The University of Tennessee Press, 1994.p. 124-148.

GORDON, Beverly. Victorian Fancywork in the American Home: Fantasy and Accomodation. In: MOTZ, Marilyn Ferris;BROWNE, Pat.Making the american home. Middle-class women \& domestic material culture 1840-1940. Bowling Green/Ohio: Bowling Green State University Popular Press, 1988. p. 48-68.

GRAHAM, Sandra Lauderdale. O impasse da escravatura: prostitutas escravas, suas senhoras e a lei brasileira de 1871. Acervo. Revista do Arquivo Nacional-Estudos de gênero, Rio de Janeiro, v. 9, $\mathrm{n}$. 1-2, p. 53-66, jan./dez. 1996. 
GRAZIA,Victoria de;FURLOUGH, Ellen (Ed.). The sex of things:gender and consumption in historical perspective or you are seduced by the sex appeal of the inorganic. Berkeley:University of California Press, 1996.

HECK, Marlene Elizabeth. "Appearance and Effect is Everything”. The James River Houses of Samuel, Joseph, and George Cabell. In:THOMPSON, Eleanor McD. The american bome. Material culture, domestic space, and family life. (A Winterthur Book).Winterthur:Henry Francis du Pont Winterthur Museum, 1998. p. 5-23

HOMEM, Maria Cecília Naclério. O palacete paulistano e outras formas urbanas de morar da elite cafeeira. 1867-1918. São Paulo: Martins Fontes, 1996.

KINCHIN, Juliet. Interiors: Nineteenth-Century Essays on the Masculine and the Feminine Room. In:KIRKHAM, Pat.(Ed.).The gendered object. Manchester:Manchester University Press, 1996.p. 1229.

KIRKHAM, Pat (Ed.). The gendered object. Manchester: Manchester University Press, 1996.

LAWRENCE, Roderick J.A More Humane History of Homes. In:ALTMAN, Irwin;WERNER, Carol M. Home environments: human behavior and environment. New York: Plenum Press, 1985. p. 113132.

LEMOS, Carlos Alberto Cerqueira.Alvenaria burguesa - breve história da arquitetura residencial de tijolos em São Paulo a partir do ciclo econômico liderado pelo cafá. $2^{\circledR}$ ed. São Paulo: Nobel, 1989.

LEMOS, Carlos Alberto Cerqueira. Casa paulista: história das moradias anteriores ao ecletismo trazido pelo café. São Paulo: Edusp, 1999a.

LEMOS, Carlos Alberto Cerqueira. Cozinhas, etc. - um estudo sobre as zonas de serviço da casa paulista. $2^{n}$ ed. São Paulo: Perspectiva, 1978.

LEMOS, Carlos Alberto Cerqueira.A república ensina a morar (melbor). São Paulo:Hucitec, 1999b. (Estudos Históricos, 39).

LIMA,Tania Andrade. Chá e simpatia: uma estratégia de gênero no Rio de Janeiro oitocentista.Anais do Museu Paulista. História e Cultura Material. Nova Série, v. 5, p. 93-129, jan./dez. 1997.

LIMA,Tania Andrade. Pratos e mais pratos: louças domésticas, divisões culturais e limites sociais no Rio de Janeiro, século XIX.Anais do Museu Paulista. História e Cultura Matéria, Nova Série,v.3, p. 129-191, jan./dez. 1995.

MALUF, Marina. Ruídos da memória. São Paulo: Siciliano, 1995.

MALUF, Marina; MOTT, Maria Lúcia. Recônditos do mundo feminino. In: SEVCENKO, Nicolau (Ed.). História da vida privada no Brasil. São Paulo: Companhia das Letras, 1998. v. 3, p. 367-421.

MARLING, Karal Ann. From the Quilt to the Neocolonial Photograph: the Arts of the Home in an Age of Transition. In:FOY,Jessica H.; MARLING, KaralAnn. The arts and the american bome, 18901930. Knoxville:The University of Tennessee Press, 1994. p. 1-13. 
McKELLER, Susie. Guns: the Last 'Frontier on the Road to Equality'? In: KIRKHAM, Pat. (Ed.). The gendered object. Manchester: Manchester University Press, 1996. p. 70-79.

MELLO e SOUZA, Gilda de .O espírito das roupas: a moda no século dezenove. São Paulo:Companhia das Letras, 1987.

MULVEY, Laura. Pandora:Topographies of the Mask and Curiosity. In: COLOMINA, Beatriz (Ed.). Sexuality \& space. Princeton: Princeton Architectural Press, 1992. p. 53-71.

ODDY, Nicholas. Bicycles. In: KIRKHAM, Pat. (Ed.). The gendered object. Manchester: Manchester University Press, 1996. p. 60-69.

PRIORE, Mary Del. O corpo feminino e o amor: um olhar. In: D'INCAO, Maria Ângela (Org.). Amor e família no Brasil. São Paulo: Contexto, 1989.p. 31-56.

PRIORE, Mary Del. Ritos da vida privada. In: MELLO e SOUZA, Laura de (Org.). História da vida privada no Brasil: cotidiano e vida privada na América Portuguesa. São Paulo: Companhia das Letras, 1997. v. 1, p. 275-330.

QUEIRÓS, Maria Isaura Pereira de. Introdução. In: BERNARDES, Maria Thereza Caiuby Crescenti. Mulberes de ontem? Rio de Janeiro - Século XIX. São Paulo:T.A. Queiroz, 1989. p. XI.

REDE, Marcelo. História a partir das coisas: tendências recentes nos estudos de cultura material. Anais do Museu Paulista, São Paulo, v. 4, p. 265-282, jan./dez. 1996.

RETALLACK, G. Bruce. Razors, Shaving and Gender Construction: an Inquiry into the Material Culture of Shaving. Material History Review, Spring, n. 49, p. 4-19, 1999.

RIGGINS, Stephen Harold (Ed.). Introduction. In: The socialness of things: essays on the socio-semiotics of objects. Berlim: Mouton de Gruyter, 1994. p. 9-22.

ROBERTSON,Una.An illustrated history of the bousewife, 1650-1950. [S.1.]:Sutton Publishing, 1997.

RODGERS, Silvia.Women's Space in a Men's House: the British House of Commons. In:ARDENER, Shirley (Ed.). Women and space. Ground rules and social maps. Oxford: Berg, 1997. p. 46-69.

ROTH, Rodris. Scrapbook Houses. A Late Nineteenth-Century Children's View of the American Home. In:THOMPSON, Eleonor McD. (Ed.). The american home. Material culture, domestic space, and family life. (A Winterthur Book).Winterthur: Henry Francis du Pont Winterthur Museum, 1998. p. 301-323.

SAHLINS, Marshall. Cultura e razão prática. Rio de Janeiro: Zahar, 1979.

SAIA, Luís. Morada paulista. São Paulo: Perspectiva, 1972. (Col. debates)

SAMARA, Eni de Mesquita. O discurso e a construção da identidade de gênero na América Latina. São Paulo: Cedhal, 1996. Série cursos e eventos.

SAMARA, Eni de Mesquita.Família e vida doméstica no Brasil: do engenho aos cafezais. São Paulo: Humanitas, 1999. (Estudos Cedhal; 10 - Nova Série). 
SAMARA, Eni de Mesquita. Gênero e construção do simbólico na literatura. Acervo. Revista do Arquivo Nacional-Estudos de Gênero, Rio de Janeiro, v. 9, n. 1-2, p. 125-136, jan./dez. 1996.

SAMARA, Eni de Mesquita.A história da família no Brasil. Revista Brasileira de História. Família e grupos de convívio, São Paulo, v. 9, n. 17, p. 7-35, set.88/fev.89.

SAMARA, Eni de Mesquita. Mão-de-obra feminina, oportunidades e mercado de trabalho, no Brasil do século XIX. In: SAMARA, Eni de Mesquita (Org.). As idéias e os números do gênero. Argentina, Brasil e Chile no século XIX. São Paulo: Hucitec/Cedhal/Vitae, 1997. p. 23-61.

SCANLON, Jennifer. The ladies' home journal, gender, and the promises of consumer culture. New York: London: Routledge, 1995.

SCHOESER, Mary. Legging it. In: KIRKHAM, Pat (Ed.). The gendered object. Manchester: Manchester University Press, 1996. p. 133-140.

SCHPUN, Mônica Raisa.Beleza em jogo. Cultura física e comportamento em São Paulo nos anos 20. São Paulo: Boitempo Editorial / Senac, 1999.

SCHWARTZ, Hillel. Hearing Aids: Sweet Nothings, or an Ear for an Ear. In: KIRKHAM, Pat (Ed.). The gendered object. Manchester: Manchester University Press, 1996. p. 43-59.

SENNETT, Richard. Carne e pedra: o corpo e a cidade na civilização ocidental. Rio de Janeiro: Record, 1997.

SILVA, Maria Beatriz Nizza da. Mulheres e patrimônio familiar no Brasil no fim do período colonial. Acervo. Revista do Arquivo Nacional-Estudos de Gênero, Rio de Janeiro, v. 9, n. 1-2, p. 85-98, jan./ dez. 1996.

SKAR, Sarah Lund. Andean Women and the Concept of Space/Time. In:ARDENER, Shirley (Ed.). Women and space. Ground rules and social maps. Oxford: Berg, 1997. p. 31-45.

SOIHET, Rachel. Mulheres em busca de novos espaços e relações de gênero. Acervo. Revista do Arquivo Nacional-Estudos de Gênero, Rio de Janeiro, v. 9, n. 1-2, p. 99-124, jan./dez. 1996.

THOMPSON, Eleonor McD. (Ed.). The american bome. Material culture, domestic space, and family life. (A Winterthur Book). Winterthur/Delaware: Henry Francis du Pont Winterthur Museum, 1998.

VAZ, Maria Luísa. Mulheres da elite cafeeira em São Paulo - conciliação e resistência - 1890/1930. 1995. Dissertação (Mestrado em História Social) - Faculdade de Filosofia, Letras e Ciências Humanas, Universidade de São Paulo, São Paulo, 1995.

WAJDA, Shirley Teresa.The Artistic Portrait Photograph. In: FOY, Jessica H.; MARLING, Karal Ann. The arts and the american home, 1890-1930. Knoxville:The University of Tennessee Press, 1994. p. 165-182.

WALL, diZerega Diana. The archaeology of gender. Separating the spheres in urban America. (Interdisciplinary Contributions to Archaeology). New York: Plenum Press, 1994. 
WINSHIP, Marion Nelson. Safety and Danger in a Puritan Home. Life in the Hull-Sewall House, 16761717. In:THOMPSON, Eleonor McD. (Ed.). The american home. Material culture, domestic space, and family life. (A Winterthur Book). Winterthur/Delaware: Henry Francis du Pont Winterthur Museum, 1998. p. 257-271.

Artigo reapresentado em 3/2003. Aprovado em 7/2003. 
Estudos de Cultura Material: uma vertente francesa

Marcelo Rede

Surgida na França, no âmbito dos estudos antropológicos e sociológicos, uma tendência recente de análise da cultura material se firma como uma alternativa à tradição anglo-americana dos material culture studies. Este artigo procura definir suas características predominantes, avaliando suas possibilidades e seus limites para o trabalho do historiador.

PALAVRAS-CHAVE: Cultura Material. Sociologia. França.

Anais do Museu Paulista. São Paulo. N. Sér. v. 8/9. p.281-291 (2000-2001). Editado em 2003.

Material Culture Studies: a French stream

Marcelo Rede

Arisen in France, in the scope of the anthropological and sociological studies, a recent analysis tendency of the material culture settles as an alternative to the Anglo-American tradition of the 'material culture studies'. This article wants to define its predominant characteristics, evaluating its possibilities and its limits for the historian's work.

KEYWORDS: Material Culture. Sociology. France.

Anais do Museu Paulista. São Paulo. N. Sér. v. 8/9. p.281-291 (2000-2001). Editado em 2003.

Gênero e Cultura Material: uma introdução bibliográfica

Vânia Carneiro de Carvalho

Este artigo discute as contribuições de historiadores, curadores, arquitetos, arqueólogos, antropólogos, entre outros, na produção de um objeto de conhecimento recente- a história do gênero na perspectiva da cultura material. Á confluência das duas áreas vem enriquecendo a compreensão da natureza culturalmente sexuada das práticas sociais. Nesse casamento, no entanto, somaram-se problemas teórico-metodológicos que merecem explicitação. Apesar da abrangência do campo, especial atenção foi dada para a produção bibliográfica que trata da formação do espaço doméstico ocidental burguês. Tal recorte justifica-se por entendermos que a casa é o local privilegiado de construção do gênero através de dispositivos materiais.

PALAVRAS-CHAVE: História da Mulher. História da Família. Espaço Doméstico. Cultura Material. História do Gênero.

Anais do Museu Paulista. São Paulo. N. Sér. v. 8/9. p.293-324 (2000-2001). Editado em 2003.

Gender and Material Culture: a bibliographic introduction

Vânia Carneiro de Carvalho

This article discusses the contributions of historians, curators, architects, archaeologists, and anthropologists, among others, in the production of an object of recent knowledge - the History of Gender in the perspective of material culture. The confluence of the two areas has been enriching the comprehension of the culturally sexual nature of the social practices. In this marriage, however, theoretical-methodological matters, which deserve a word about, have been added. Such attention is due to our understanding that home is the best place for the construction of Gender through material artefacts.

KEYWORDS:Woman's History. Family's History. Domestic Space. Material Culture. Gender's History. Anais do Museu Paulista. São Paulo. N. Sér. v. 8/9. p.293-324 (2000-2001). Editado em 2003. 